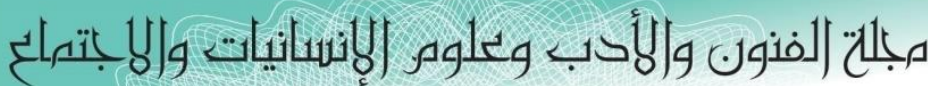

Journal of Arts, Literature, Humanities and Social Sciences

ISSN online: 2414 - 3383

ISSN print: 2616 - 3810

العدد (42) ايلول - سبتهبر 2019

\title{
هرمس والهرمسية وأثرها على الديانات
}

\author{
ا ـ إ. م. حسن طوكان عبدالله \\ كلية التربية للطوم الانسانية - جامعة ذي قار

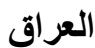 \\ hassanhistory70@yahoo.com
}

الملخص

تتردد في تاريخ الثعوب منذ ألوف السنين أسماء رجال كبار نركوا آثار في الفكر والحضارة تتناقلها الاجيال وتصفي عليها صفات عديدة قد يشترك في تكوينها كثير من الرجال في عصور و أمكنة مختلفة ، وقد تختلف حول ماهية هذه الاسماء ومز اياها و افكار ها ومن هذه الاسماء هرمس الذي لايعرف الكثيرين عن شخصيتة المو غلة في القدم رغم الوجود البارز لافكاره وكتبه في تر اثنا وثقافتنا ويشاركنا في ذلك شعوب مختلفة في الثرق و الغرب اذ يعد شخصية عالمية يعرف بأسماء مختلفة منها هرمس أخنوخ إدريس الخ ..وقد أخذ في تاريخ الثعوب صفات

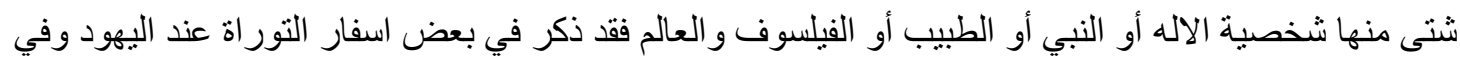
الانجيل وفي القران في سورة مريم والانبياء وذكر عند الصابئة بوذا سف وعند الفرس واليونانيين والرومان وقد اثرت الهرمسية على الديانات المصرية القديمة فقد اخذ كهان المعابد بتعليم تلامذتهم تعاليم هرمس كذلك اثرت على الديانة اليهودية خاصة فيما يخص الجانب العرفاني منها، اما الديانة المسيحية فقد امتلك المسيحيون الأو ائل كثير أ من نسخ الهرمسيات وتمتعت كتب هرمس المثلث العظمة بسلطة كبرى خلال القرون الاولى من تاريخ الكنيسة ، وكان لهرمس (إدريس ) تأثير كبير في فكرة التصوف و الفلسفة التي هي اساس تللك الافكار يضاف إلى ما نسب إليه من كتب في الفلك و التتجيم والطب فقد شاعة أفكارة بقوه بين الطوائف الاسلامية . 


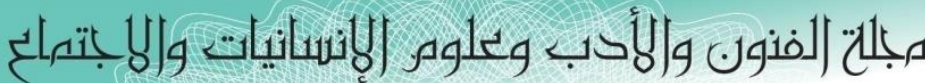

Journal of Arts, Literature, Humanities and Social Sciences

ISSN online: 2414 - 3383

ISSN print: 2616 - 3810

أيلول - سبتمبر 2019

الصدد (42)

\title{
History of Hermes and Hermes and its Influence on Religions
}

\author{
Assistant Professor. Hassan Togun Abdullah \\ Univeristy of Thi-Qar -Faculty of Education for Human Sciences \\ Iraq \\ hassanhistory70@yahoo.com
}

\begin{abstract}
In the history of peoples for thousands of years, the names of great men have left traces of thought and civilization and passed on for generations, and it is characterized by many qualities involved in the composition of many men in different ages and places. It may differ about what these names and their advantages and ideas, and these names Hermes, who does not know many about his personality old in the foot despite the prominent presence of his ideas and books in our heritage and culture, we are joined by different peoples in East and West a world figure know by various names, including Hermes,Henoch, Idris, guy has taken the history of peoples, including the gods the propjet, thedoctor, the philosopher and the world. It is mentioned in some of the books of the jaw's, in the Bible and the Quran in SuratMaryam and the prophets ,he mentioned at the Persians, Greeks, Romans ,and Sabina's .The hierarchy influenced the ancient Egyptian religions, The priests taught their disciples the teaching of ,Hermes and also in the Jewish religion, since this was evident in their influence on the Church during the first centuries of its founding either Islamic and Hermes had a great influence in the thought of Sufism and philosophy, which is the basis of those ideas added to appropriate him of books in the field of astronomy and astrology and medicine of Islamic.
\end{abstract}




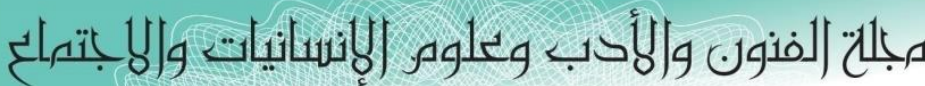

Journal of Arts, Literature, Humanities and Social Sciences

ISSN online: 2414 - 3383

ISSN print: 2616 - 3810

\section{العدد (42) أيلول - سبتمبر 2019}

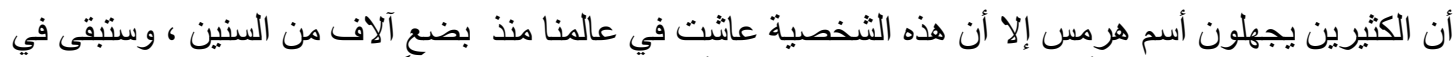

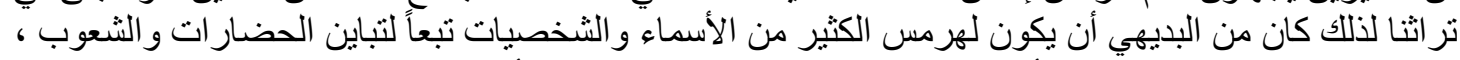

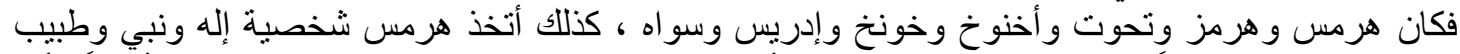

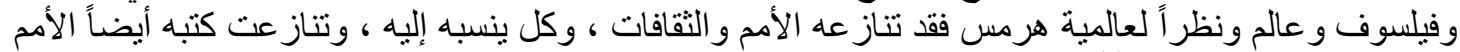

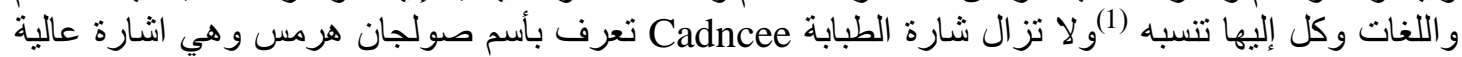

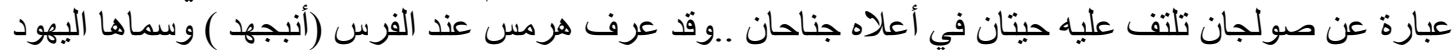
أنوش أو أنوح أو خنوخ وسماها الصابئة بوذاسيف أوساه وسماها المسلمون إدريس النبي و هناك أسماء أخرى عديدة

\section{حياة هرمسوصفاته}

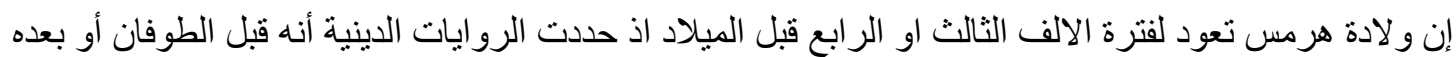

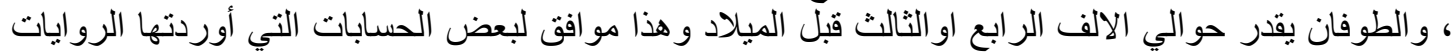

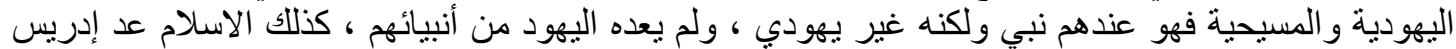

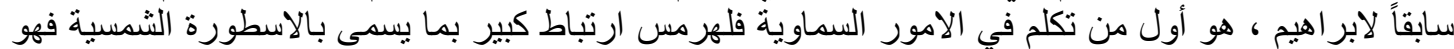

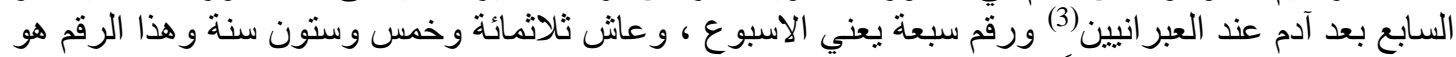

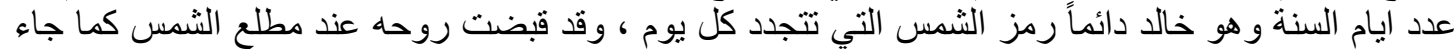

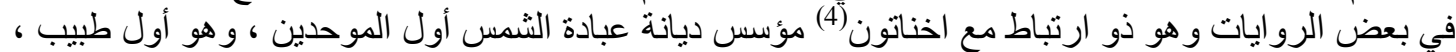

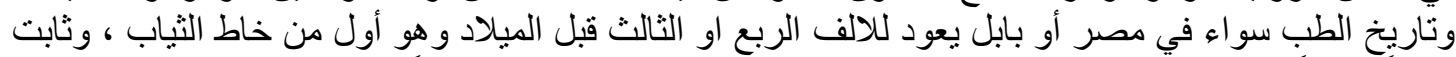

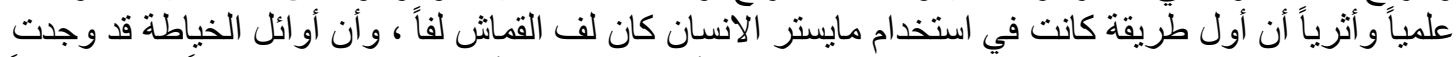

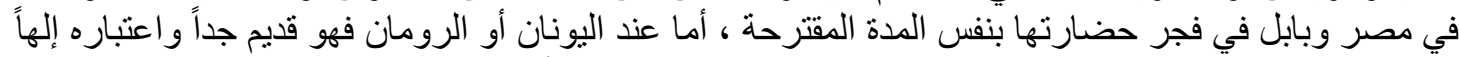

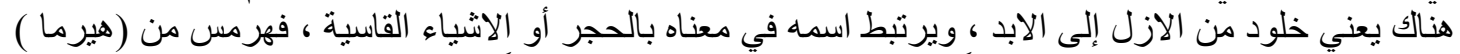

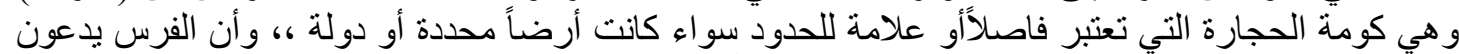

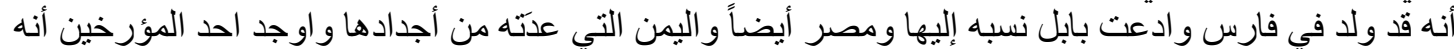

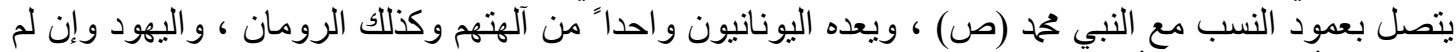

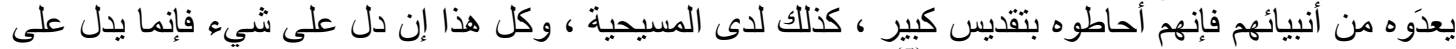

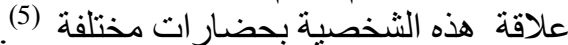

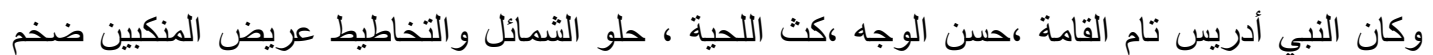

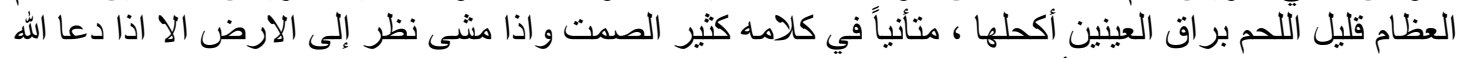

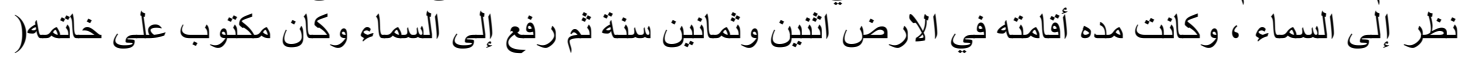

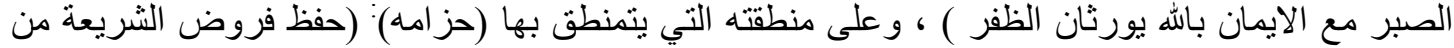

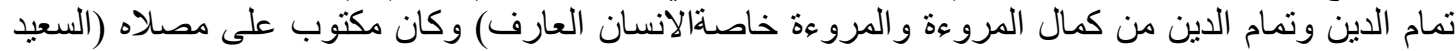

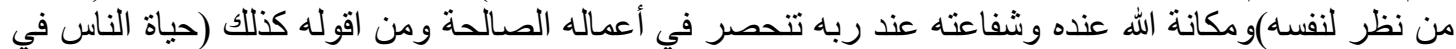

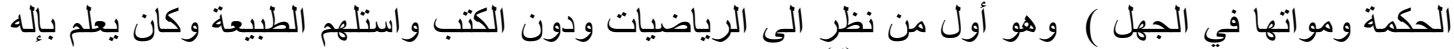
و احد له صفات ثلاثث الوجود ،و الحكمة ، الحياة (6).

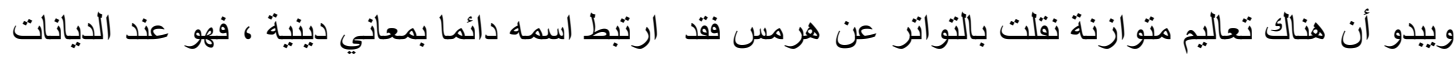

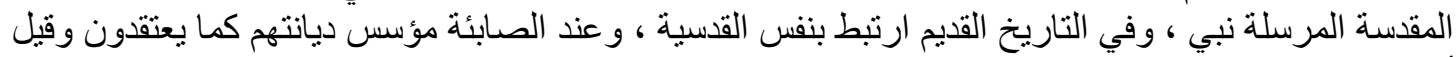

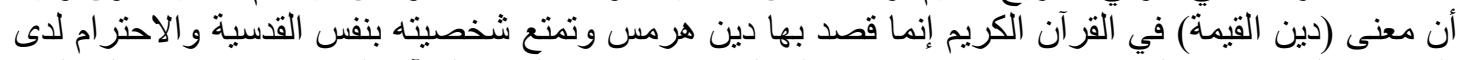

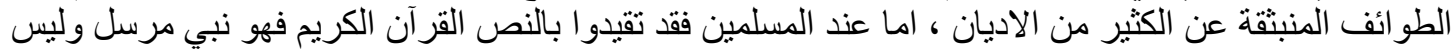

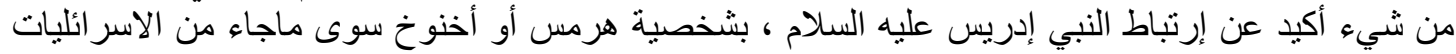

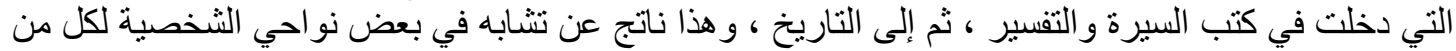




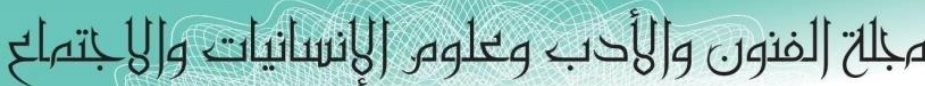

Journal of Arts, Literature, Humanities and Social Sciences

ISSN online: 2414 - 3383

ISSN print: 2616 - 3810

\section{العدد (42) أيلول - لسبتهبر 2019}

إدريس و هرمس أو اخنوخ ، وقد اثرت الهرمسية في تراث وفلسفة(7) الديانات الوثنية و اليهودية و المسيحية فعبد

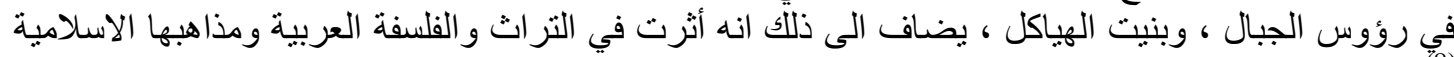

\section{مكان ولادته واصله}

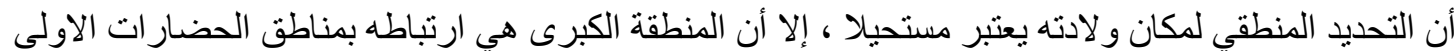

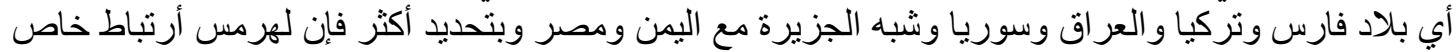

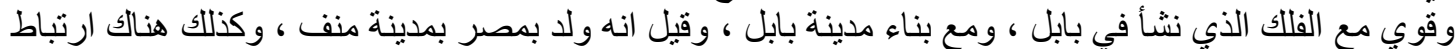

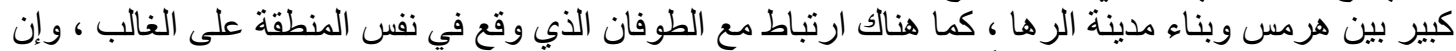

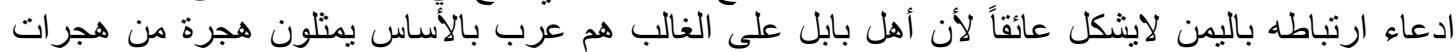

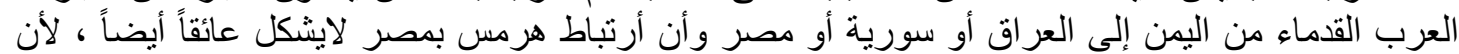
أكثر الأنبياء قد وجدوا هنالك ، و هناك رحلات وهجر القات ثابتة حدثت من العراق إلى مصر ، فهذا إبر اهيم الخليل

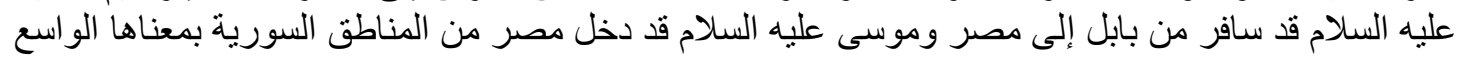

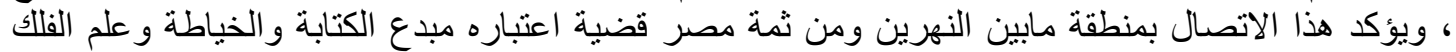
و الطب و الفلسفة وغير ذلك اذ يمكن افتر اض أن منطقة مولده منطقة الر افدين ومن ثم انتقل لمصر وثبت اعثب إطلاق

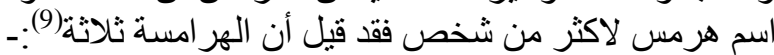

هرمس الاول:-هو الساكن بصعيد مصر الاعلى(10) وسموه هرمس الهر امسة ومولده(11) بمنف(12) وهو أول من

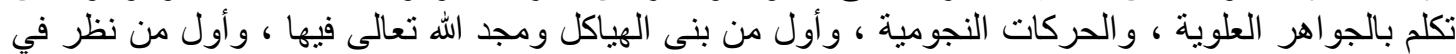

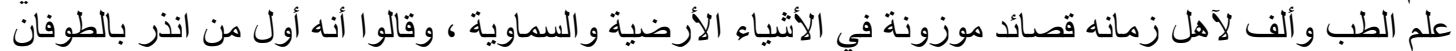

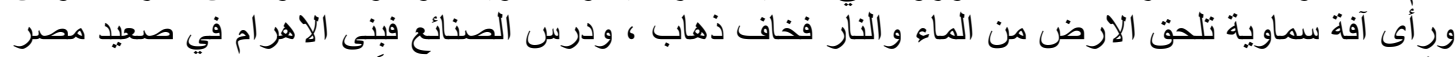

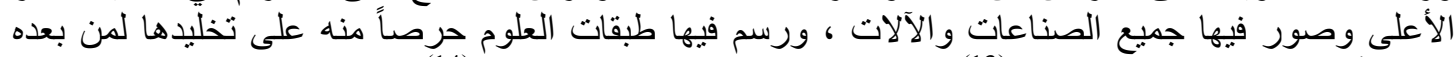

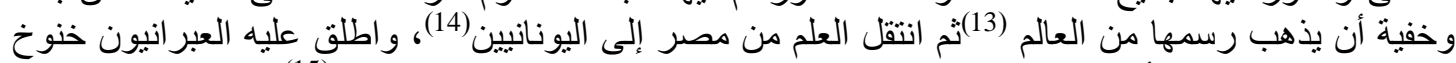

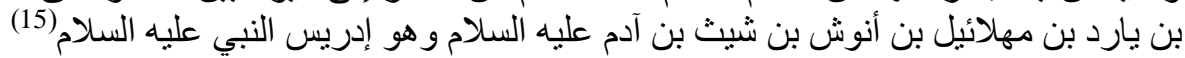

هرمس الثاني:- هرمس البابلي الذي سكن كلوذا مدينة الكلدانيين (16) هذه المدينة التي تعتبر مدينة الفلاسفة من

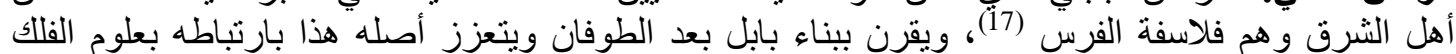
و التتجيم(18) البابلية وبيناء الهياكل أو المعابد الخاصة بالكو اكب و النجوم في بابل (19)، وبابل تعني بالنيل بالسريانية

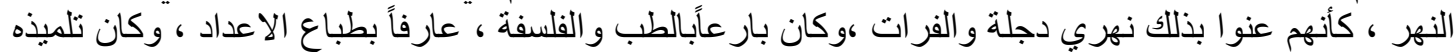

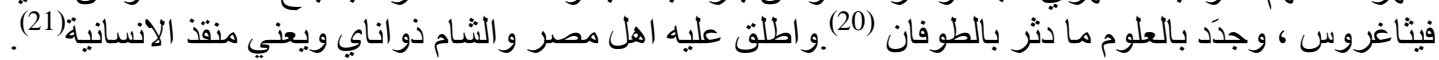

هرمس الثالث:-هرمس المصري وهو الذي يسمى طريسميجيسيس أي المثلث بالحكمة لانه جاء ثالث الهر امسة

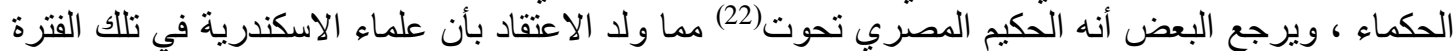

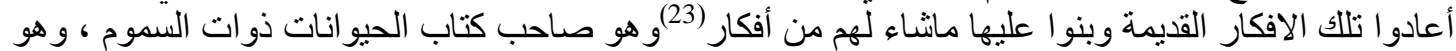

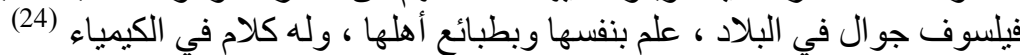

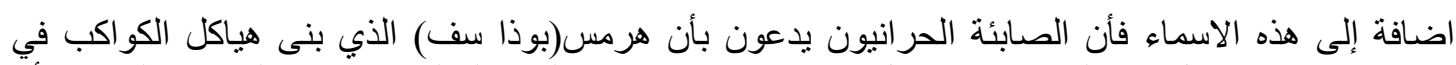

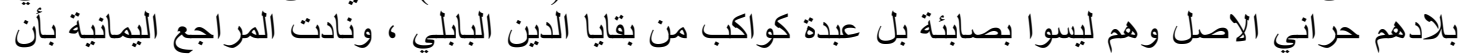

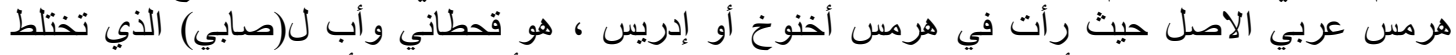

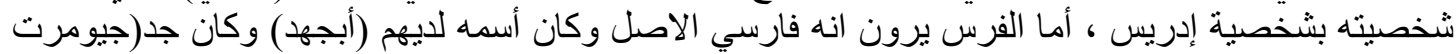

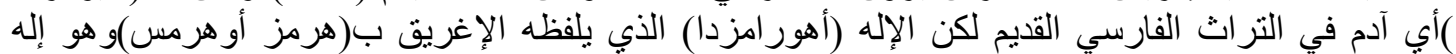

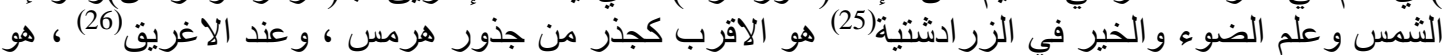

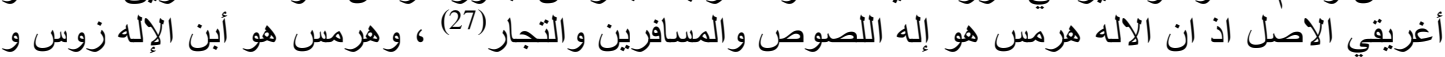

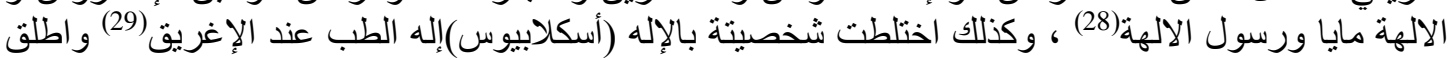




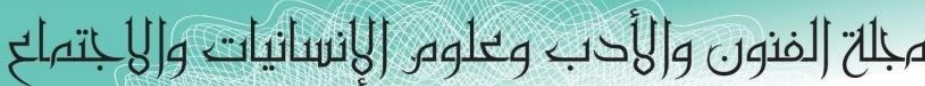

Journal of Arts, Literature, Humanities and Social Sciences

ISSN online: 2414 - 3383

ISSN print: 2616 - 3810

\section{العدد (42) أيلول - سبتهبر 2019}

عليه الرومان عطارد ومركوري وميركور وماكسيموس وعلى قول من الاقوال أندريه أو اندرياس

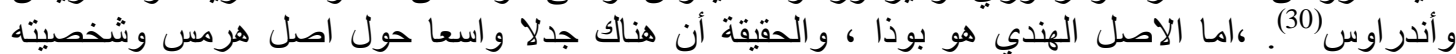

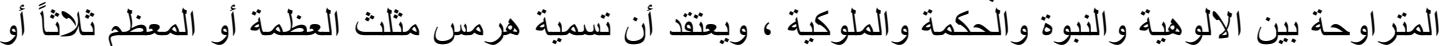
مثلث الرحمة هي ألقاب أطلقت عليه لانه جمع بين النبوة و الحكمة و الملوكية (31)

الجذور الميثولوجية لهرمس

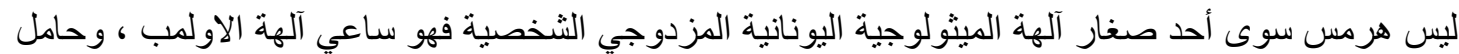

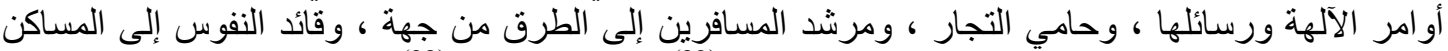

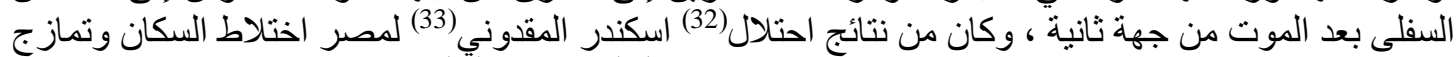

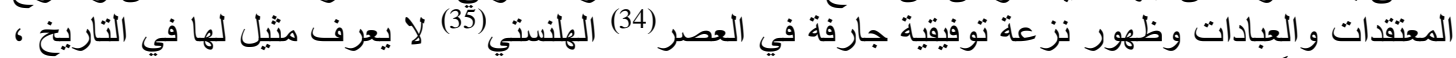

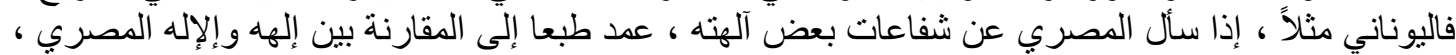

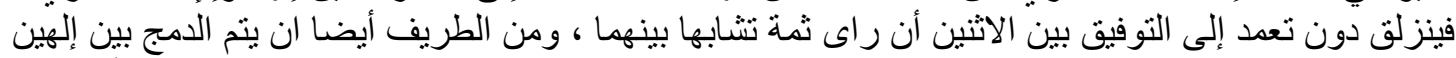

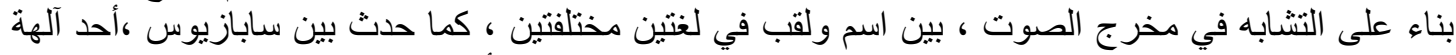

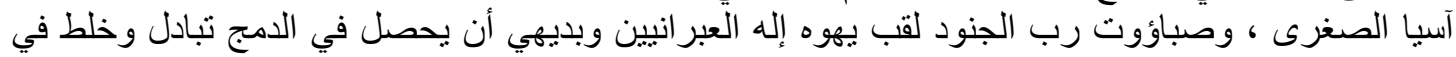

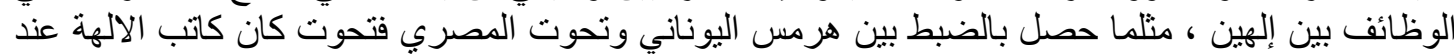

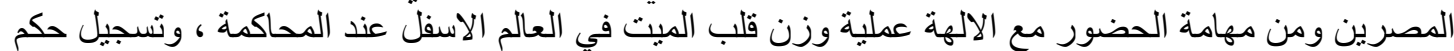

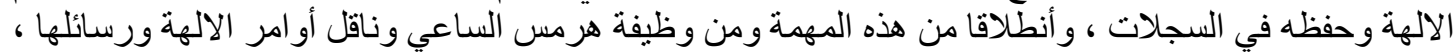

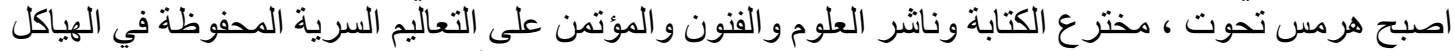

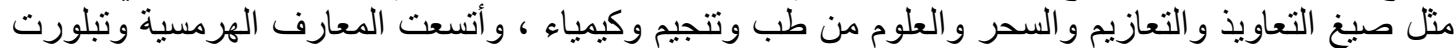
حولها أساطير القرون الهلنستية و الرومانية وخر افاتها (36).

وفاته

أن وفاته فقد أحيطت بهالة من الغموض ، فعند الأمم التي اعنبرته إلهاً لامجال للبحث في وفاته لأن الأن صفة الألو هية

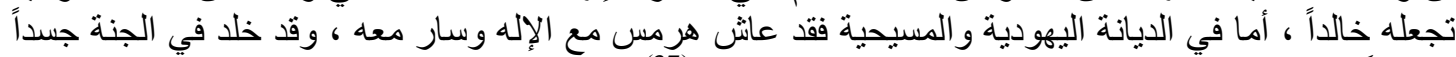

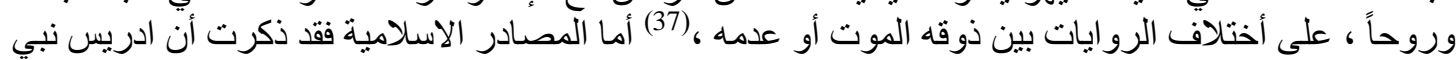

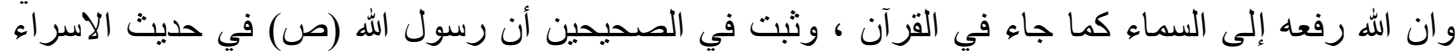

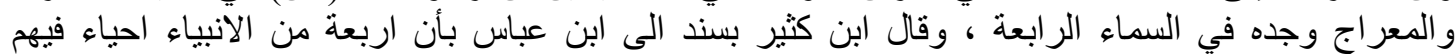

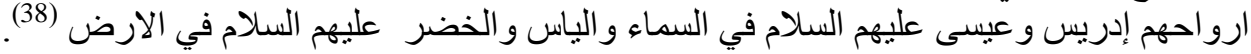

\section{الهرمسية (الهرمسيات) - ات}

تعرف الهرمسية بأنها مجموعة من المعتقدات والافكار و التطبيقات المنتقلة في الادب الهرمسي ، و المقصود

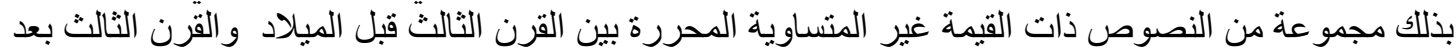

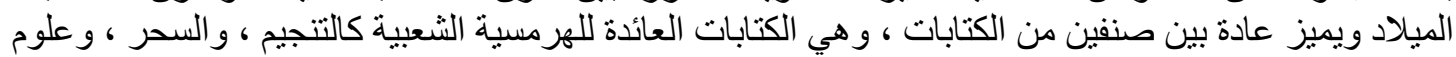

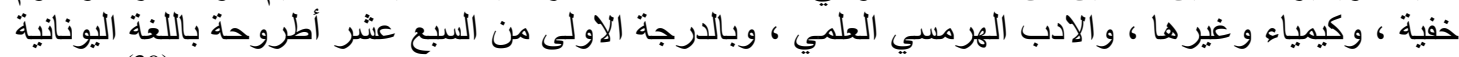

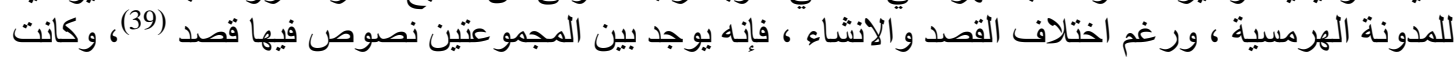

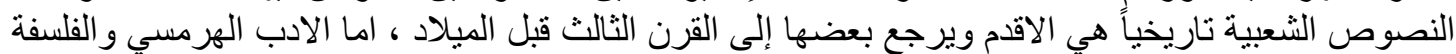

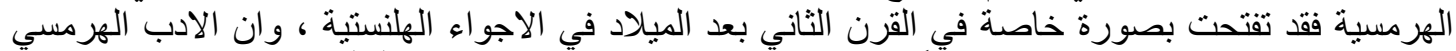

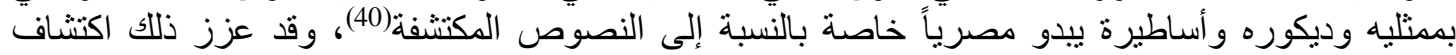

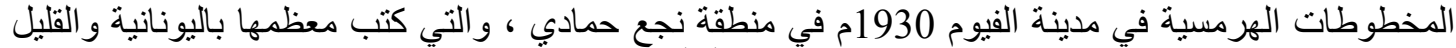
منها بالقبطية وأنها قد حوت عي على تعاليم مو غله في القدم في (41)، وقد نهلت الهرمسية الهلنستية من منبعين أساسيين 


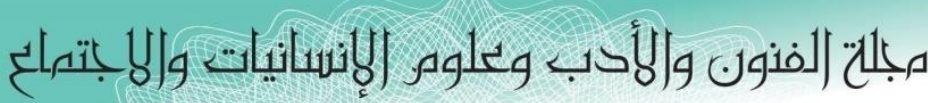
Journal of Arts, Literature, Humanities and Social Sciences

ISSN online: 2414 - 3383

ISSN print: 2616 - 3810

\section{العدد (42) أيلول - سبتهبر 2019}

هما هرمسية بابل وفارس و هرمسية مدينة الإسكندرية وأن هرمسية بابل وفارس انحدرت من سومر إلى بابل

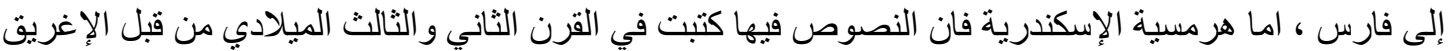

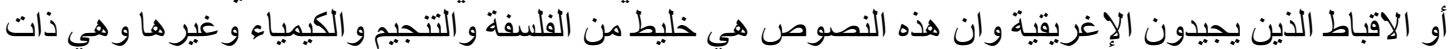
جذور شرقية فهناك نصوص ذات جذور فلسفية دينية هرمسية من الفلسفة الفيثاغورية الحديثة والانية والافلاطونية

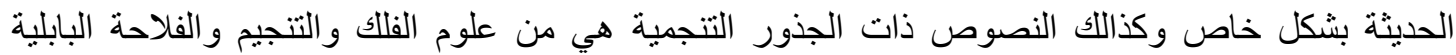

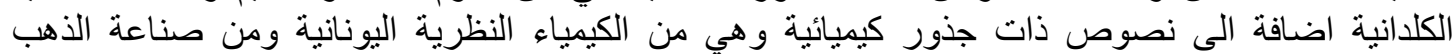

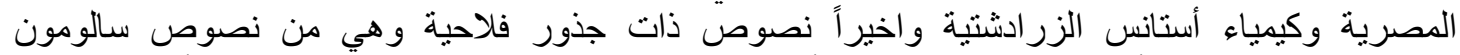

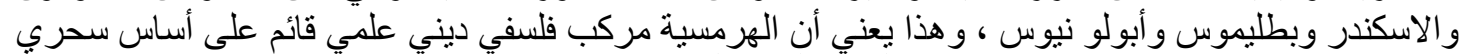

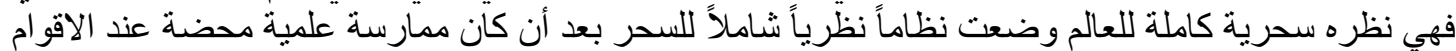

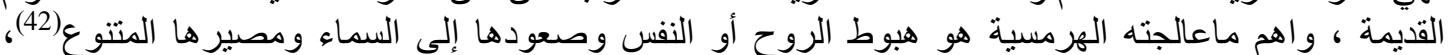

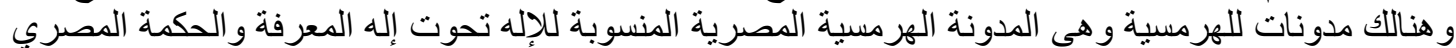

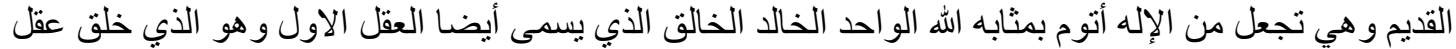

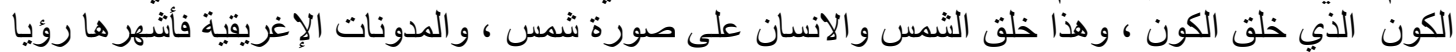

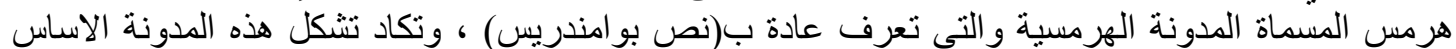

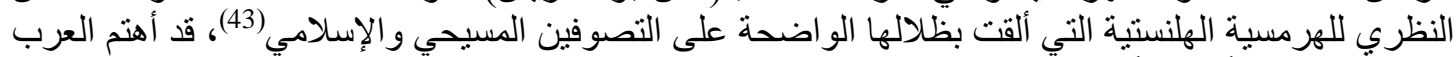

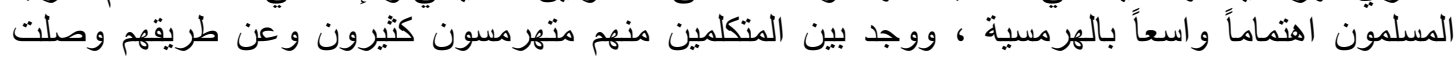

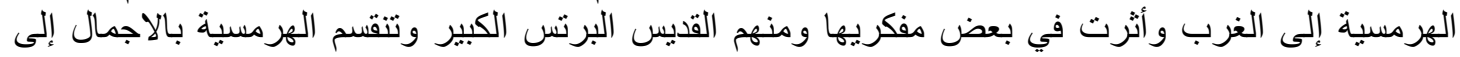

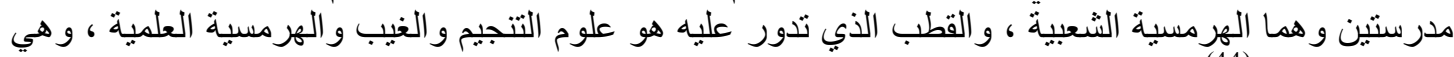
لاهوتبة وفلسفية(44).

\section{الهرمسية والدياتة المصرية القديمة}

كان المصريون الاو ائل على عقائد قديمة تدعوا إلى التوحيد الالهي قبسوه عن الرئ الرسل الذين ارسلهم الله مع تطور

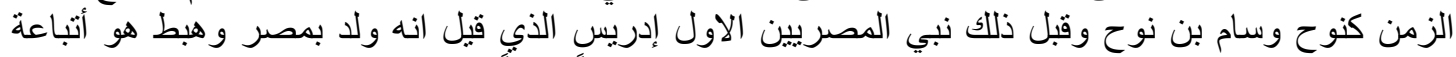

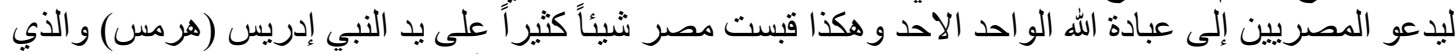

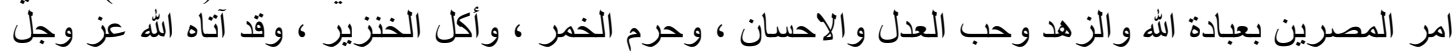

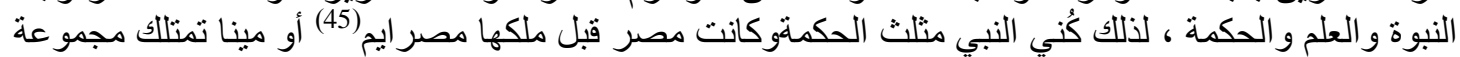

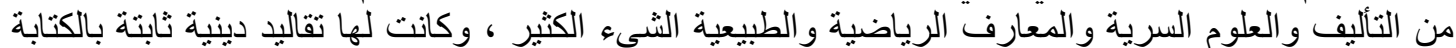

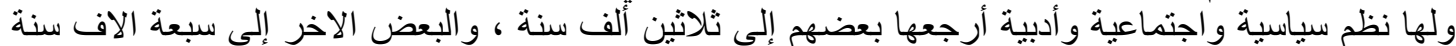

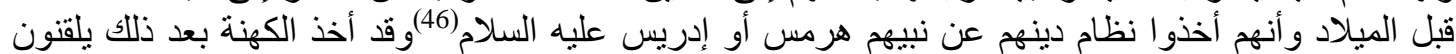

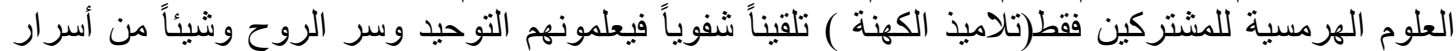

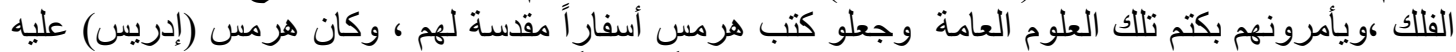

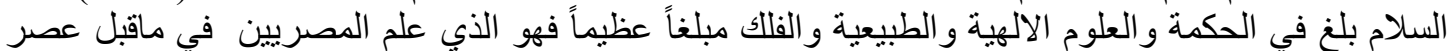

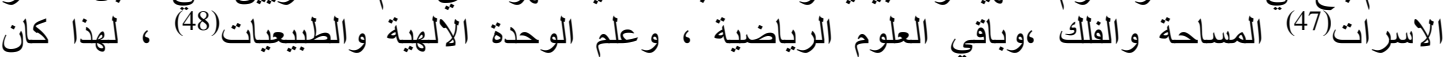

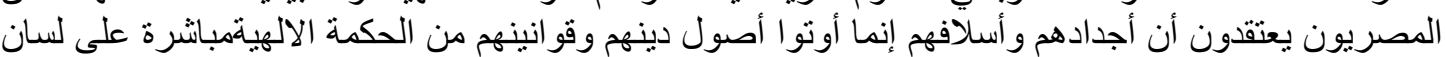

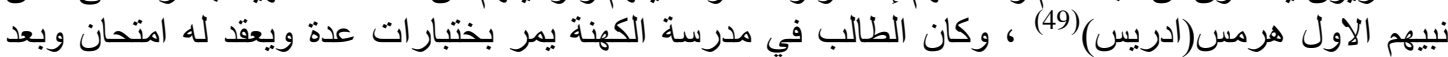

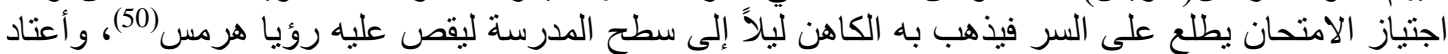

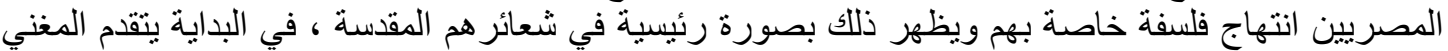

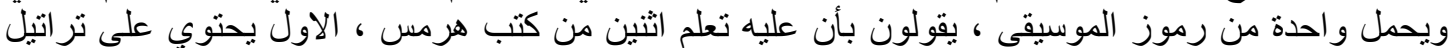

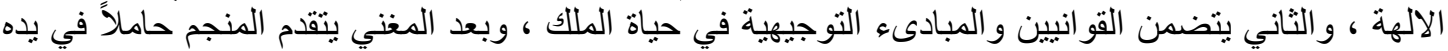

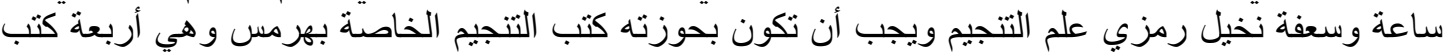

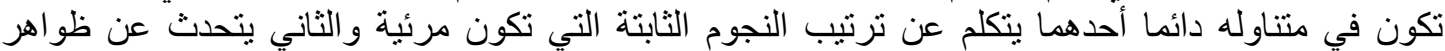

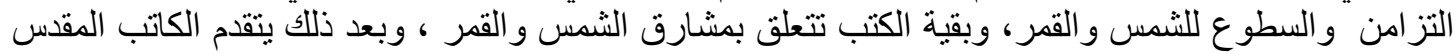




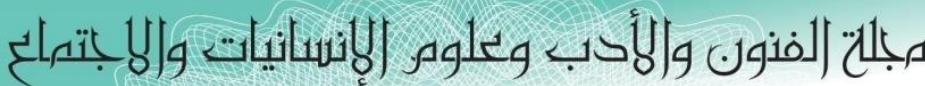

Journal of Arts, Literature, Humanities and Social Sciences

ISSN online: 2414 - 3383

ISSN print: 2616 - 3810

\section{العدد (42) أيلول - سبتهبر 2019}

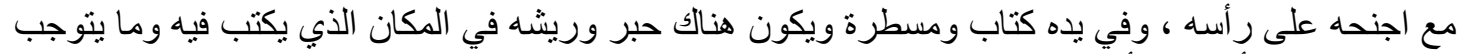

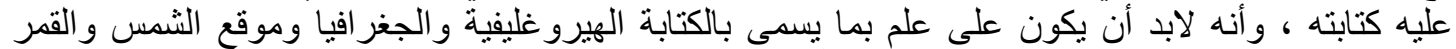

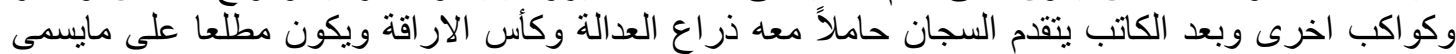

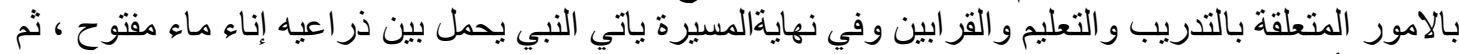

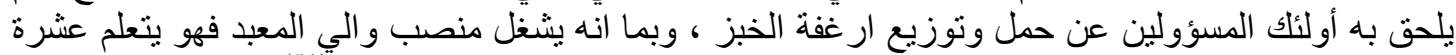

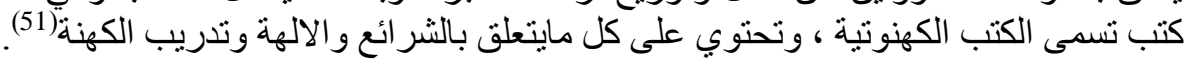

\section{الهرمسية والديانة اليهودية}

الديانة اليهودية إحدى الديانات السماوية ذات مكانه هامة في تاريخ الاديان ، ذلك أنها من أقدم الديانات التوحيدية

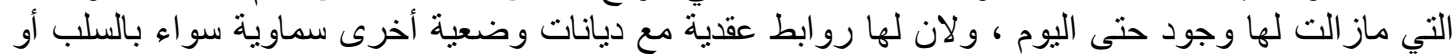

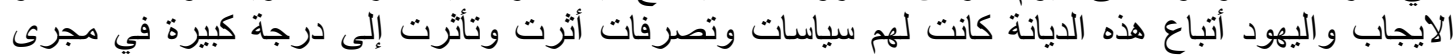

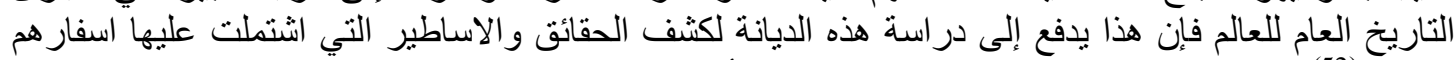

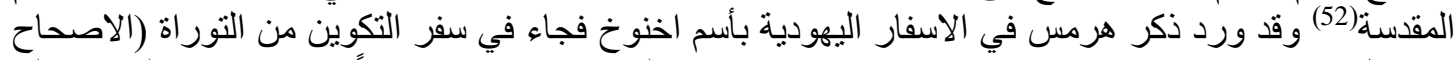

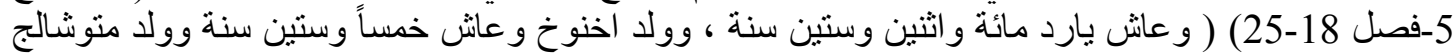

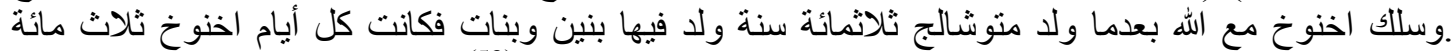

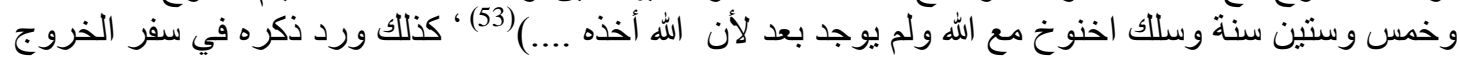

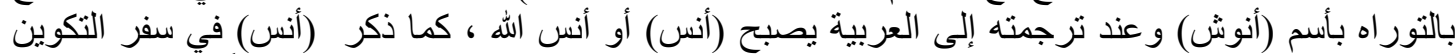

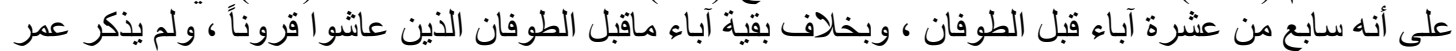

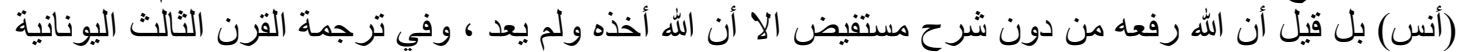

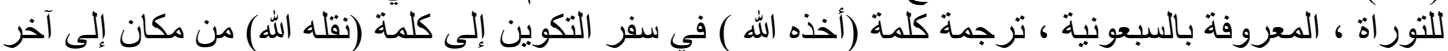

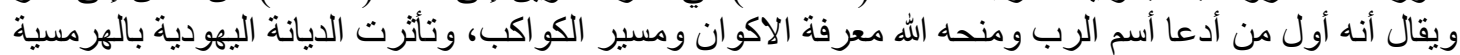

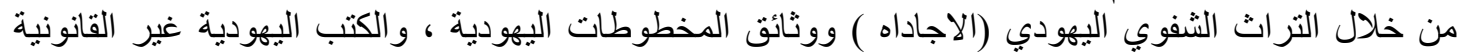

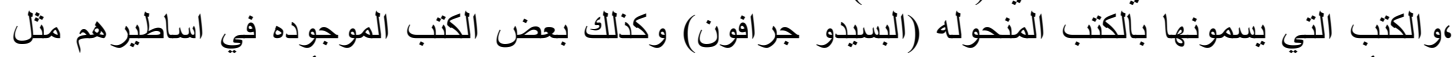

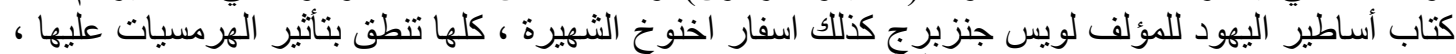

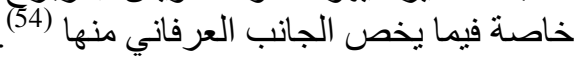

الهرمسية والديانة المسيحية

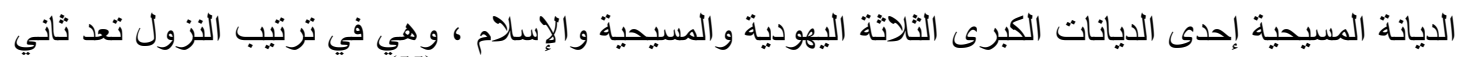

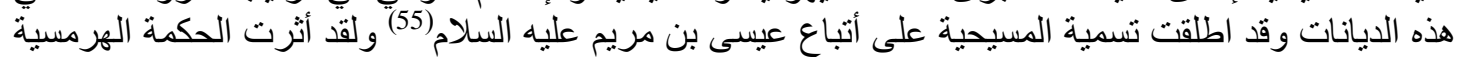

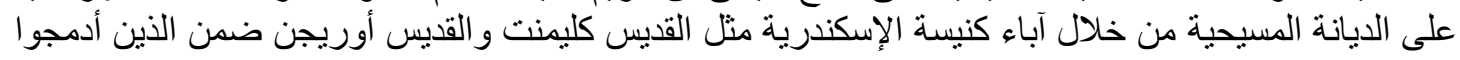

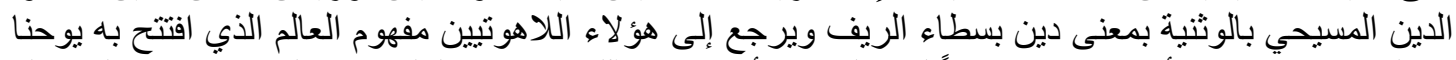

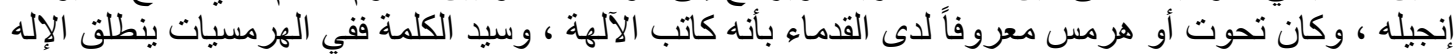

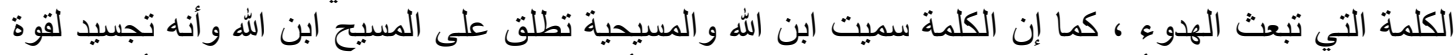

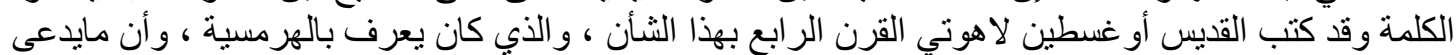

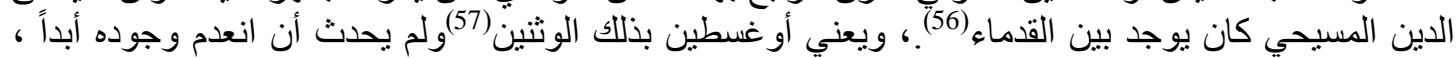

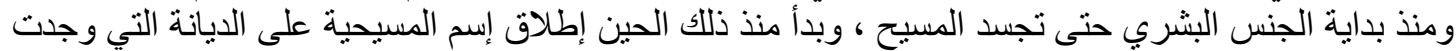

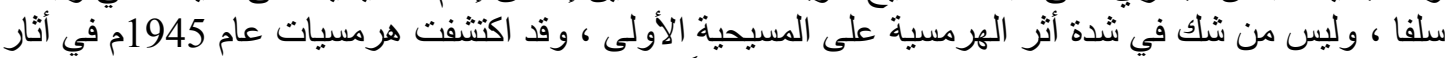

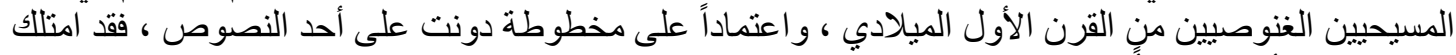

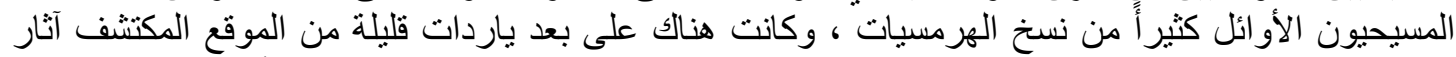

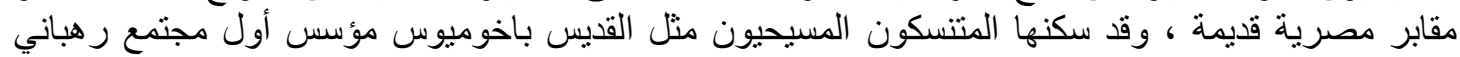

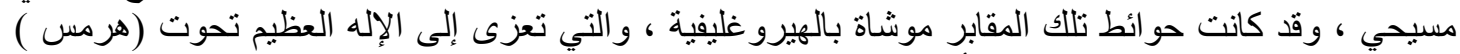

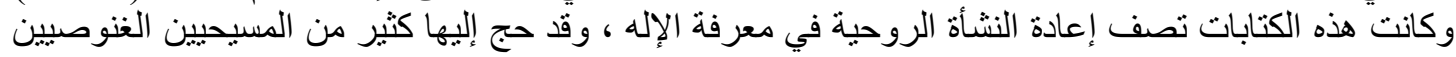




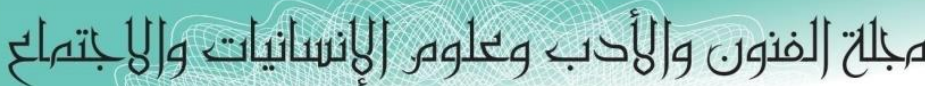

Journal of Arts, Literature, Humanities and Social Sciences

ISSN online: 2414 - 3383

ISSN print: 2616 - 3810

العدد (42) أيلول - سبتمبر 2019

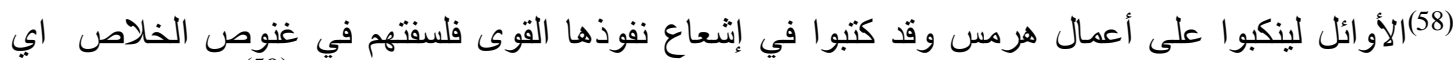

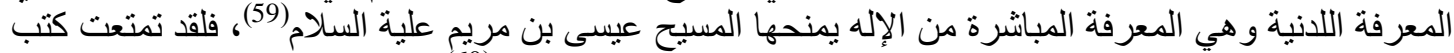

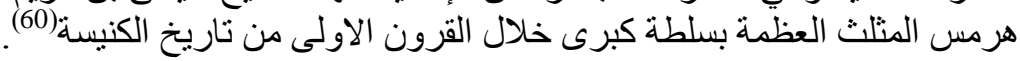

ال الهزمسية والاسلام

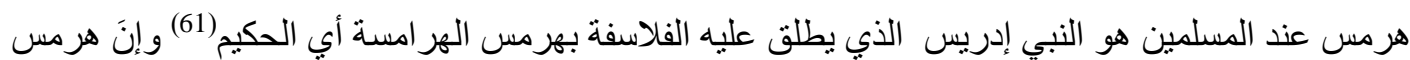

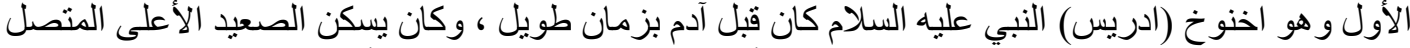

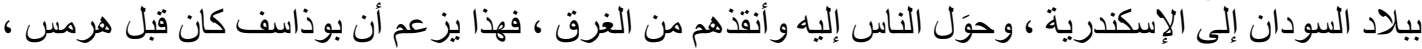

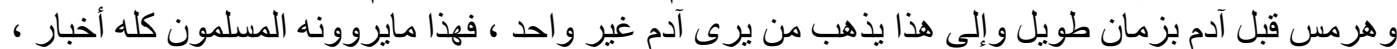

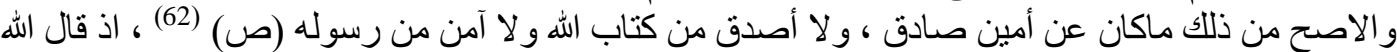

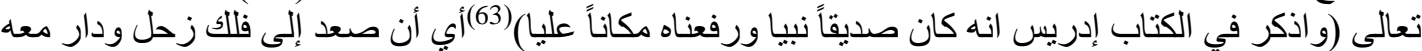

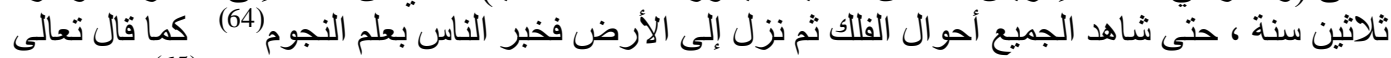

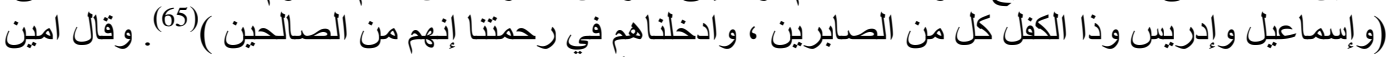

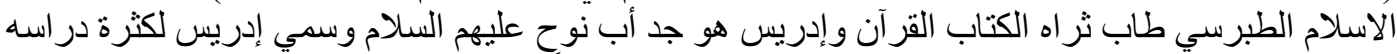

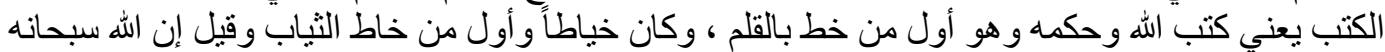

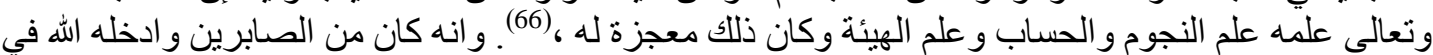

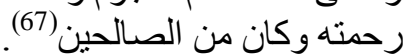

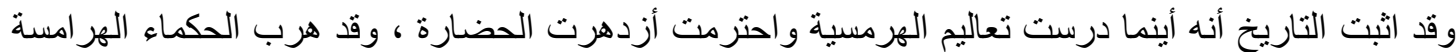

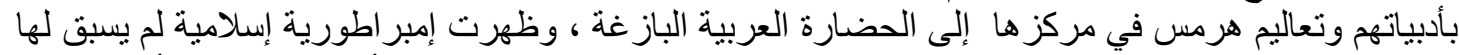

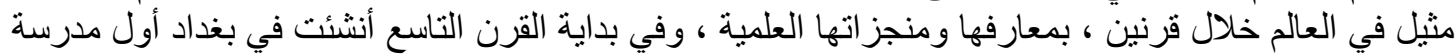

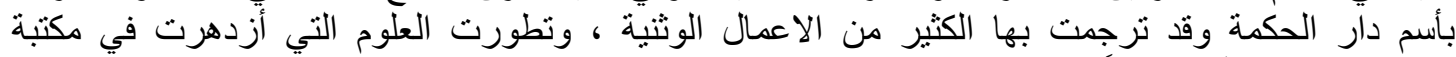

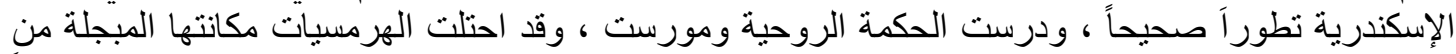

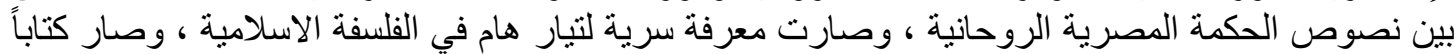

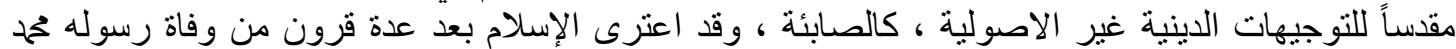

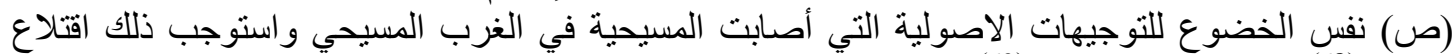

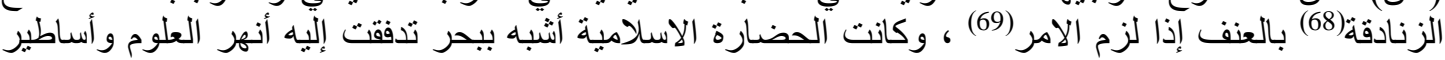

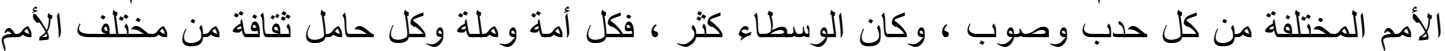

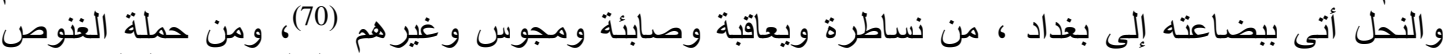

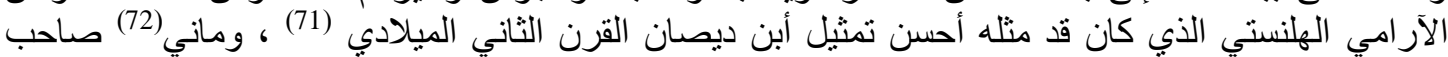

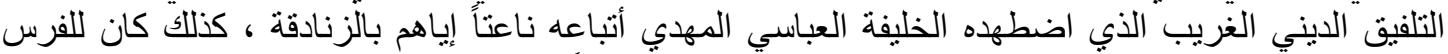

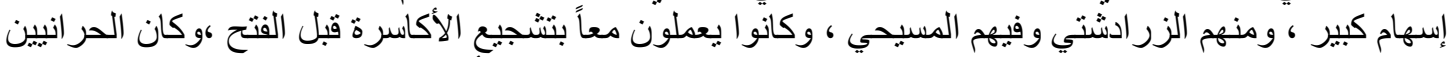

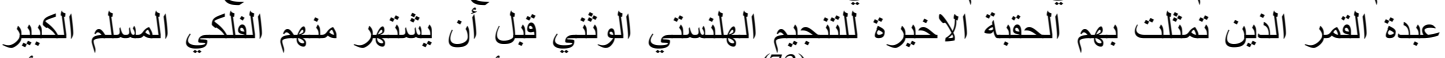

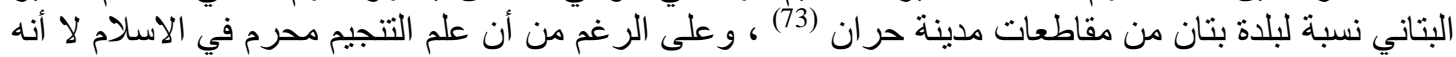

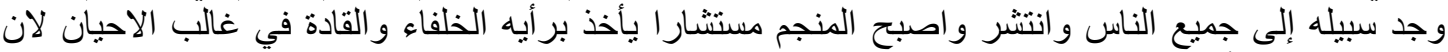

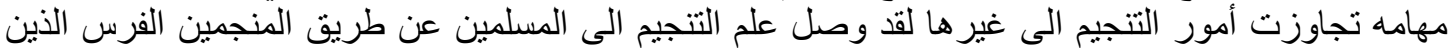

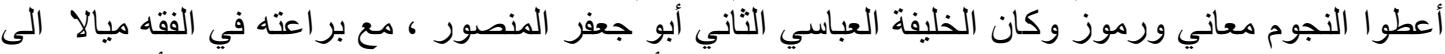

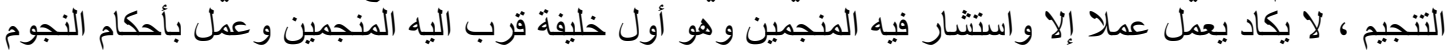

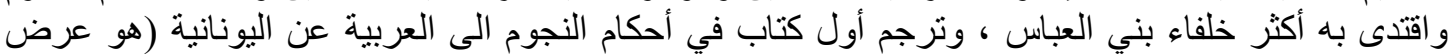

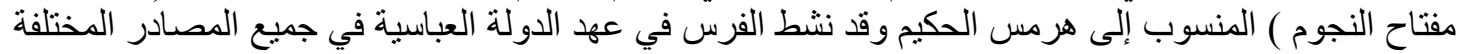

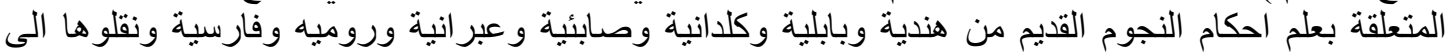

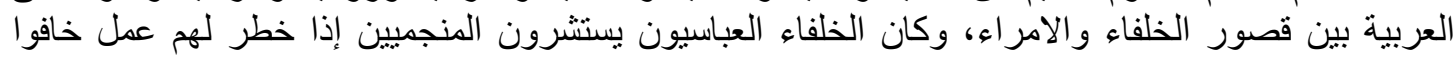

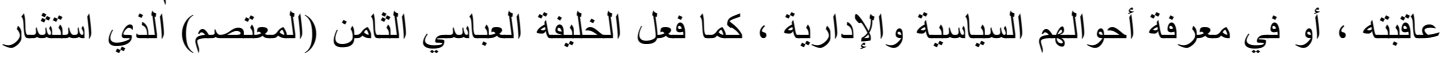




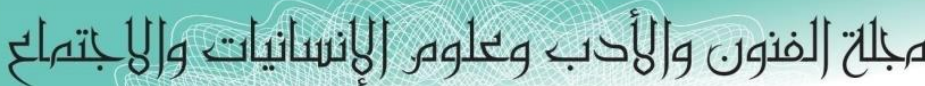

Journal of Arts, Literature, Humanities and Social Sciences

ISSN online: 2414 - 3383

ISSN print: 2616 - 3810

\section{العدد (42) ايلول - سبتمبر 2019}

المنجمين في غزو بلاد الروم فطلبوا منه التريث ولكن المعتصم لم يعتد بأقو الهم فهاجم الروم و افتتح مدينة

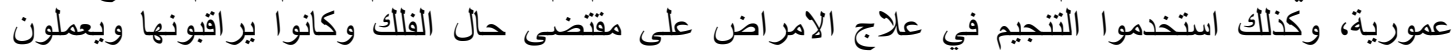

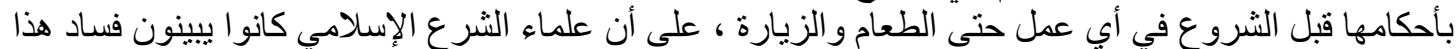

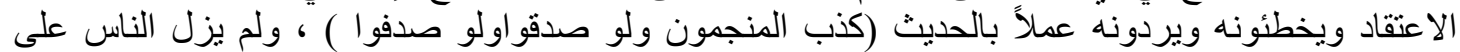

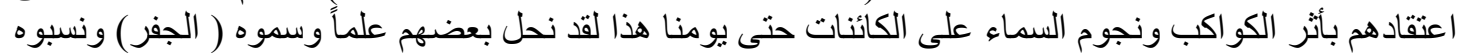

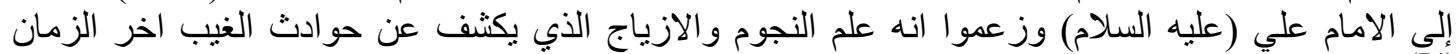

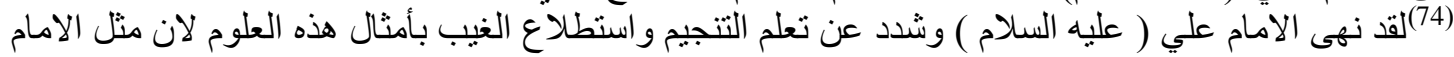

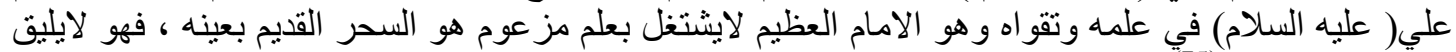

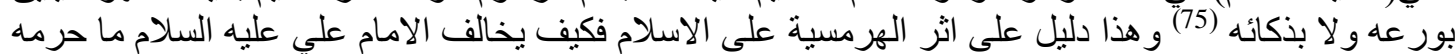

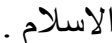

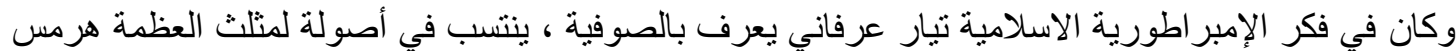

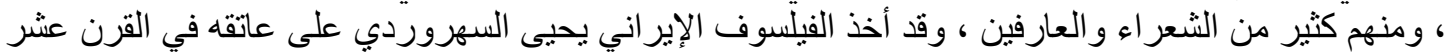

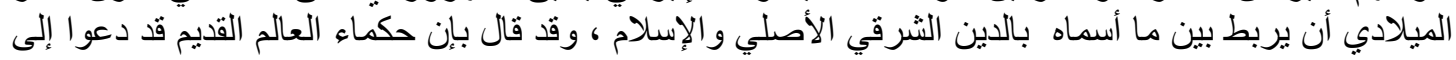

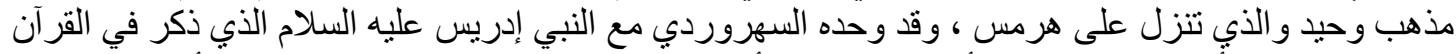

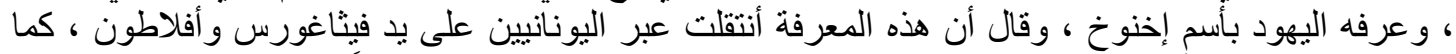

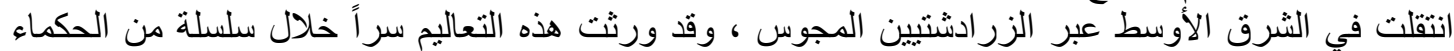

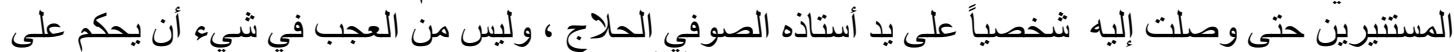

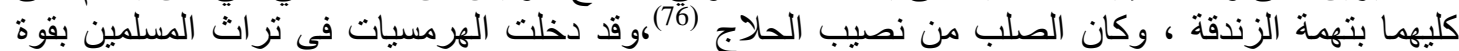

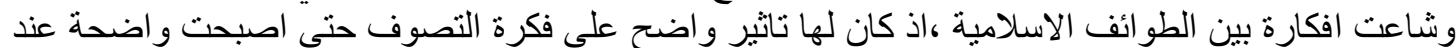

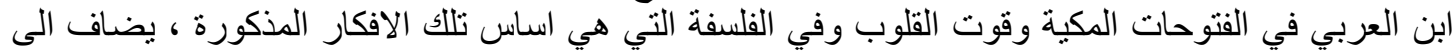

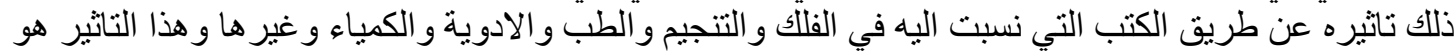

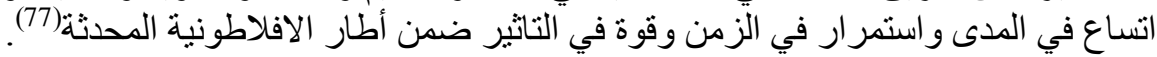

\section{الهرمسية والايانة الصابئة}

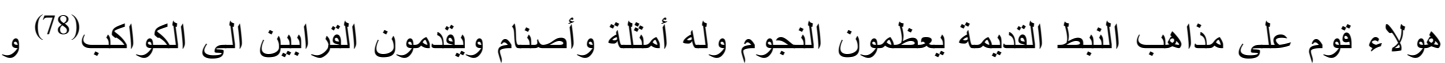

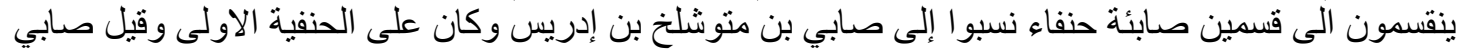

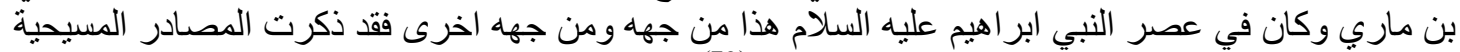

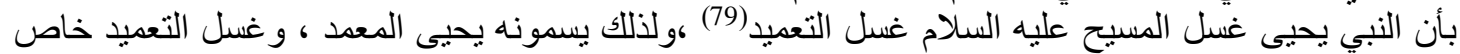

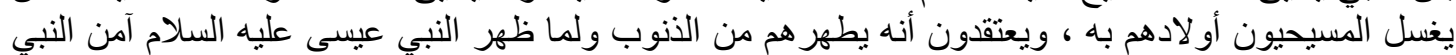

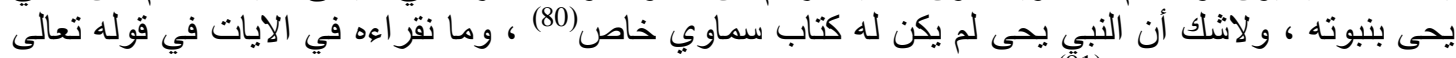

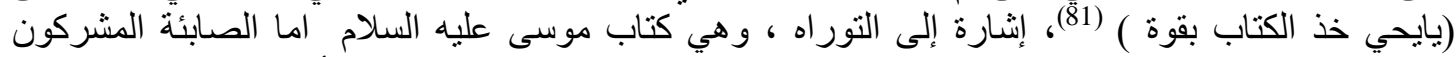

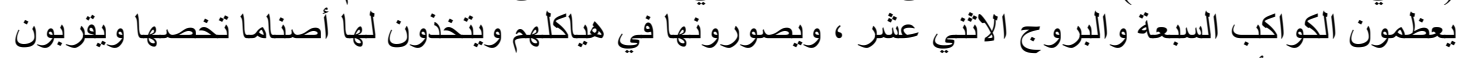

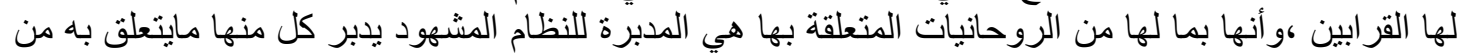

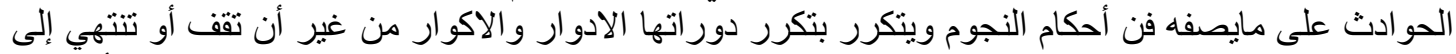

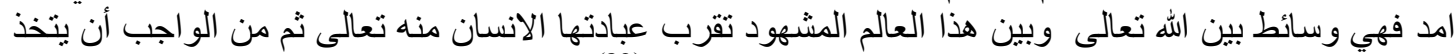

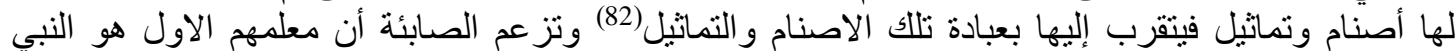

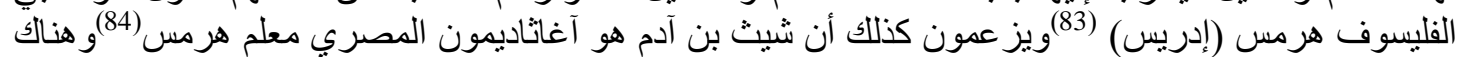

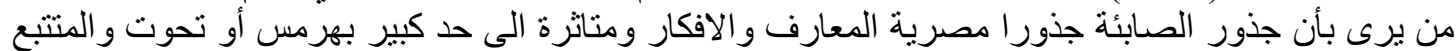

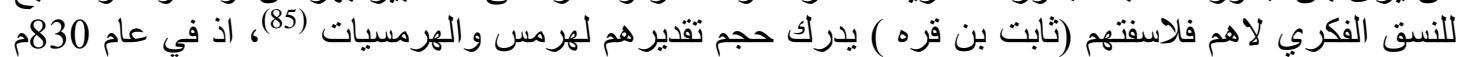

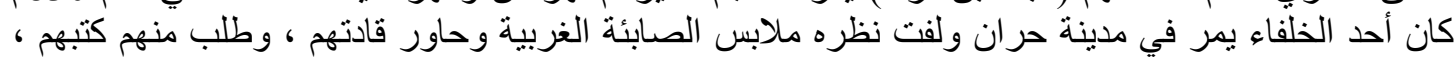

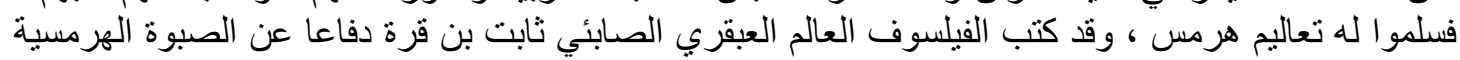

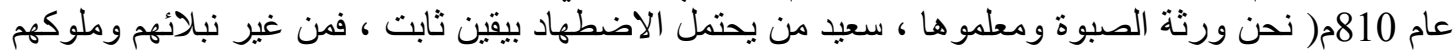




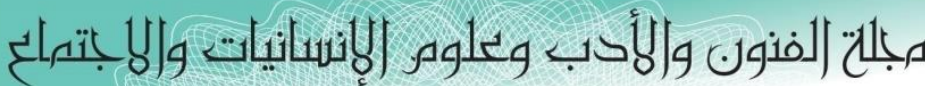

Journal of Arts, Literature, Humanities and Social Sciences

ISSN online: 2414 - 3383

ISSN print: 2616 - 3810

\section{العدد (42) أيلول - لسبتمبر 2019}

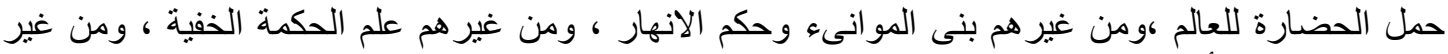

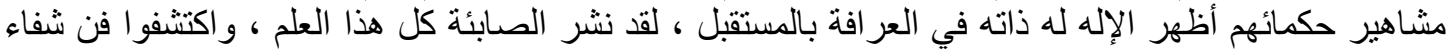

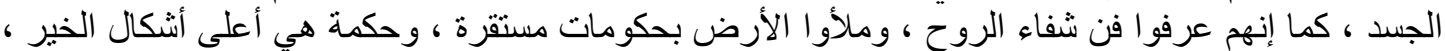

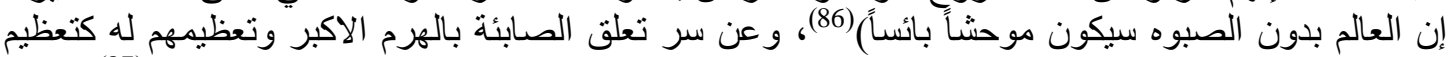

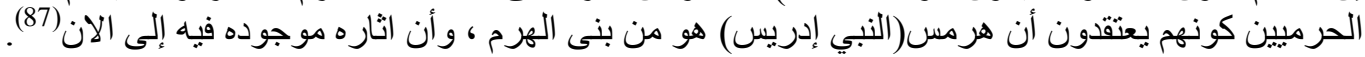

الخاتمة

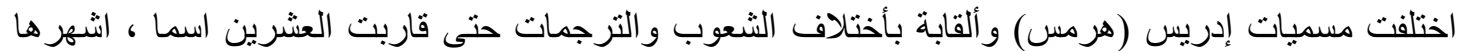

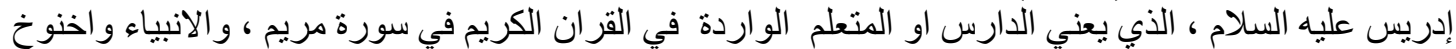

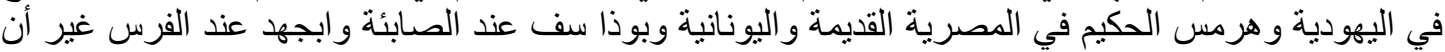

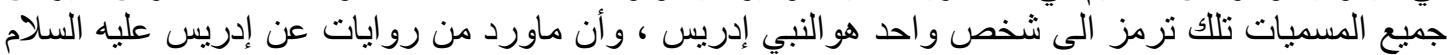

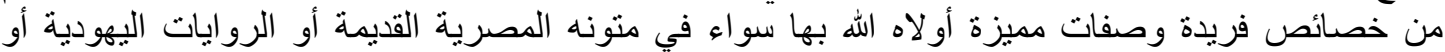

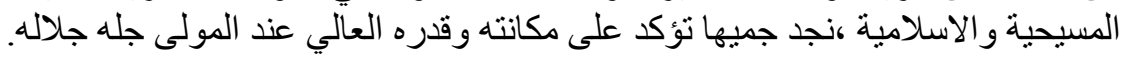

اما بالنسبة الهرمسية فهي وسيلة تطلع دارسيها على جذور المعتقدات والاساطير وخلفيات الممارسات الدينية

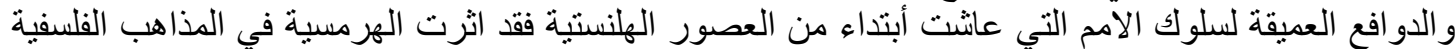

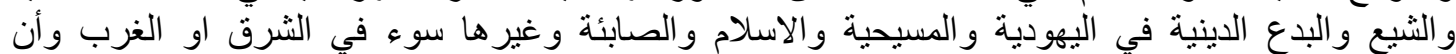

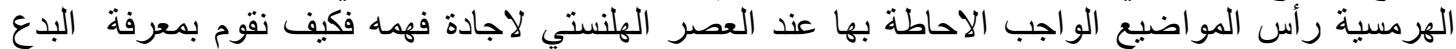

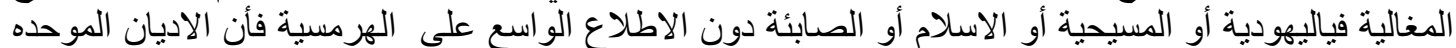

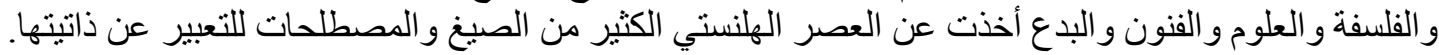

الهوامش

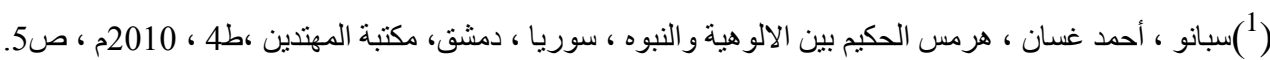

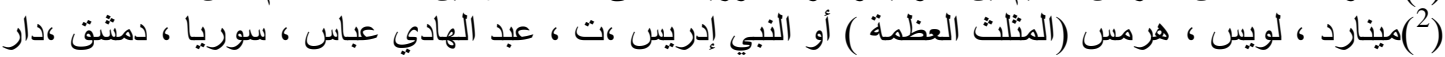

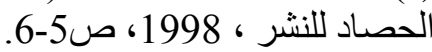

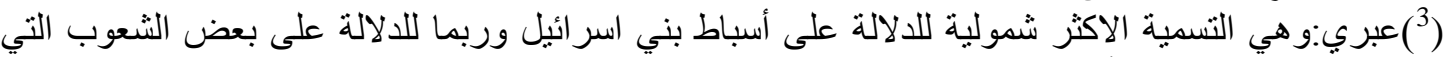

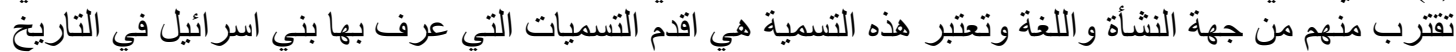

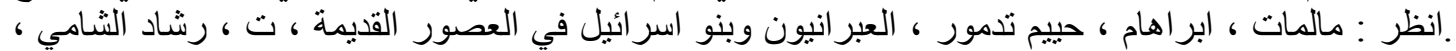

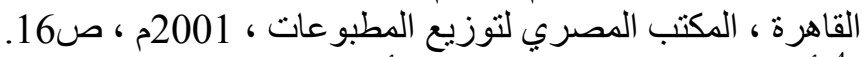

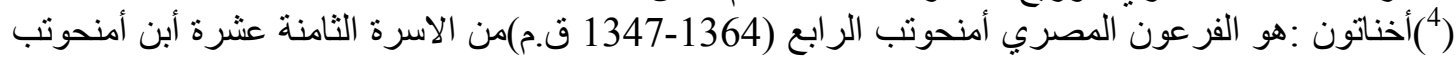

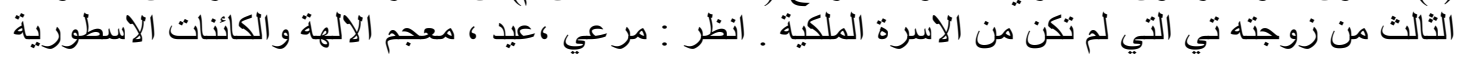

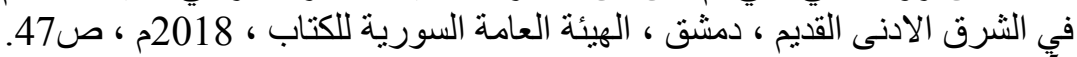

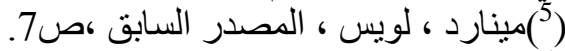

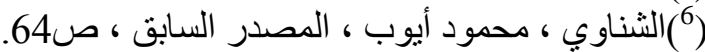

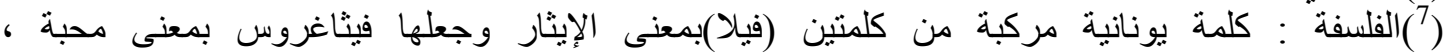

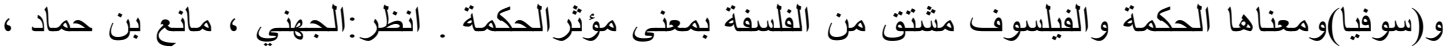

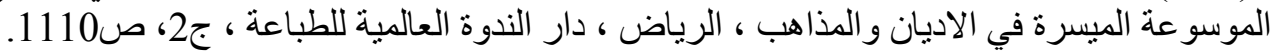

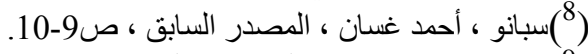

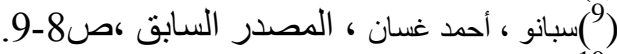
(10) درويش ، هدى ، نبي الله ادريس بين المصرية القديمة و اليهودية والاسلام ، القاهرة ،دار السلام ، 2008م، ص86. (10) 


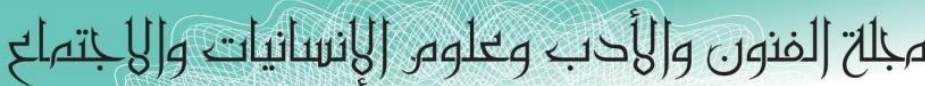

Journal of Arts, Literature, Humanities and Social Sciences

ISSN online: 2414 - 3383

ISSN print: 2616 - 3810

\section{العدد (42) أيلول - لسبتهبر 2019}

(11) الققطي ، جمال الدين أبي الحسن علي بن القاضي ، اخبار العلماء بأخبار الحكماء ،مص ، دار الكتب

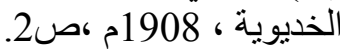

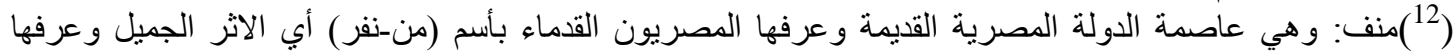

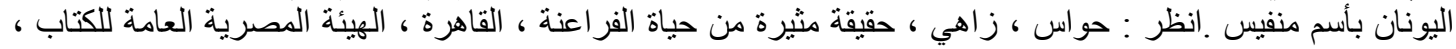

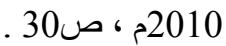

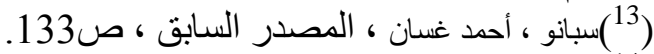

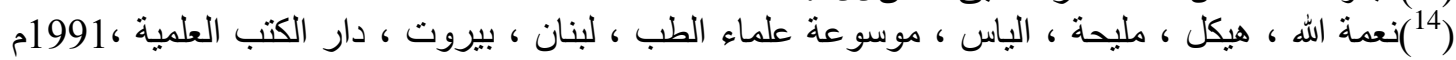
.18،

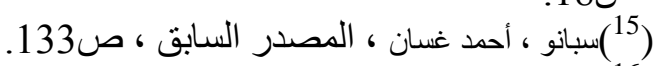

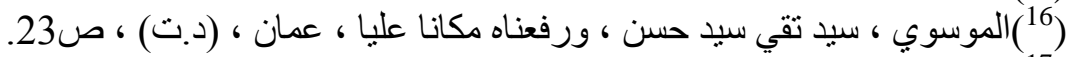

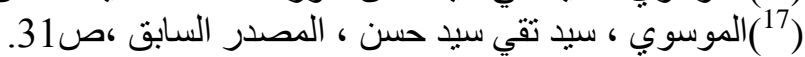
(18) التنجيم:يقصد به الاستدلال بالاحوال الفيد، الفلكية على الحوادث الارضية ـ النظر : الجهني ، مانع بن حماد ، المصدر

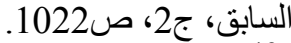

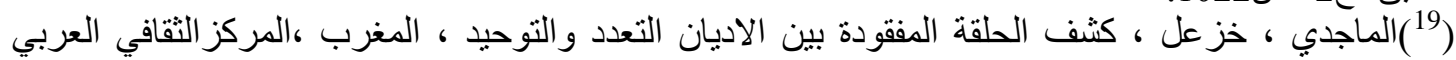

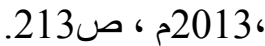

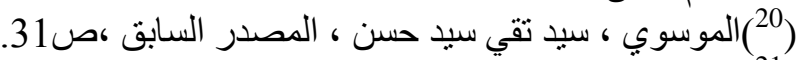

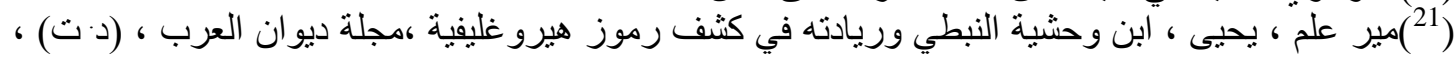

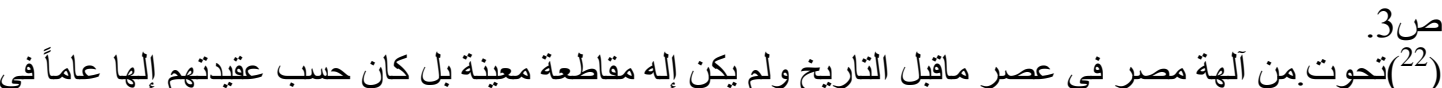

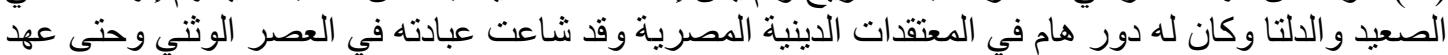

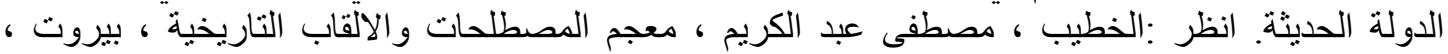

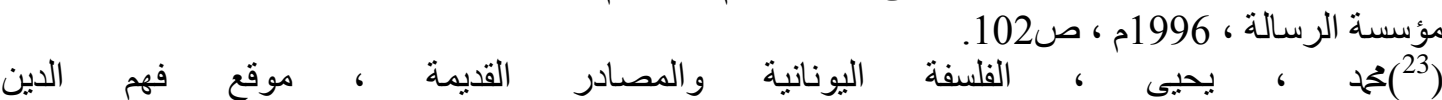
http://fahmaldin.net/index.php?id=2144

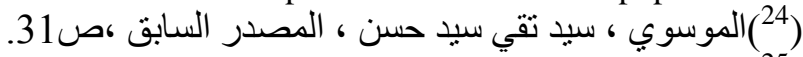

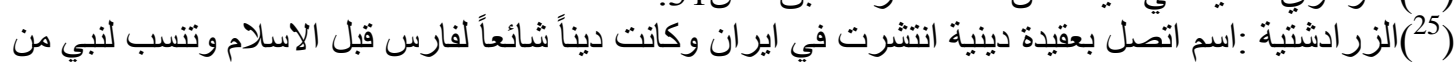

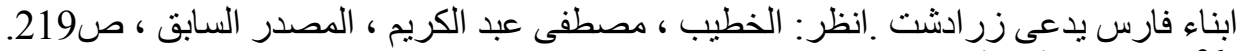

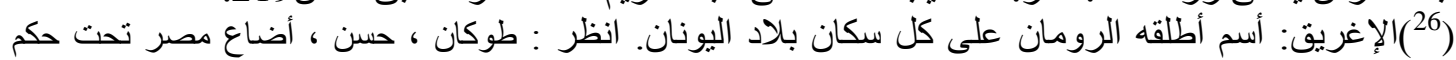

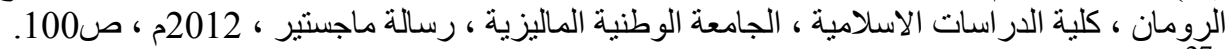

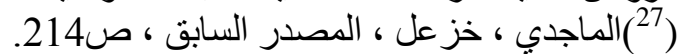

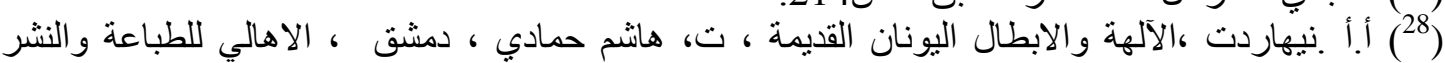

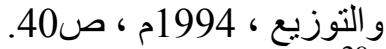

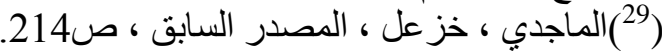

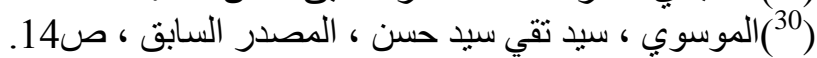

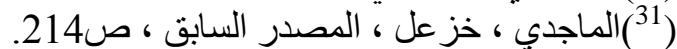
(32) هير اتي ، الاب منوديوس ، الاسكندر الكبير ، دمشق ، دار ، دار طلاس للدراسات والترجمة ، 1999م ، ص230. (230

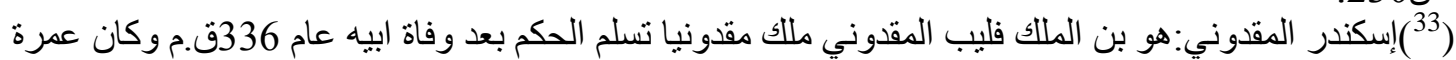

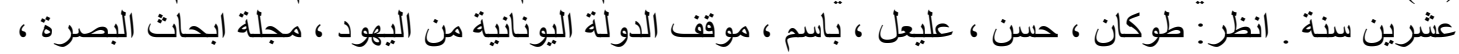

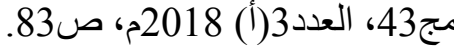
(34) هير اتي ، الاب منوديوس ، المدئ صدر السابق ، ص230. 


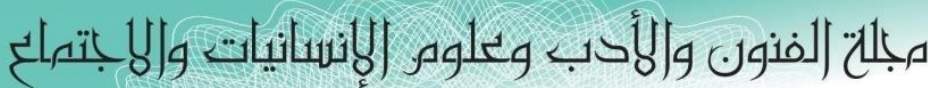

Journal of Arts, Literature, Humanities and Social Sciences

ISSN online: 2414 - 3383

ISSN print: 2616 - 3810

\section{العدد (42) أيلول - لسبتهبر 2019}

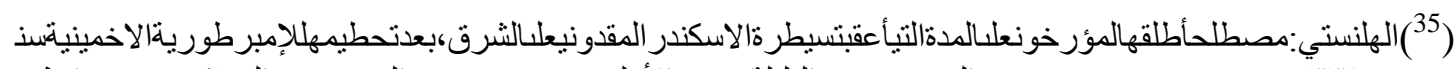

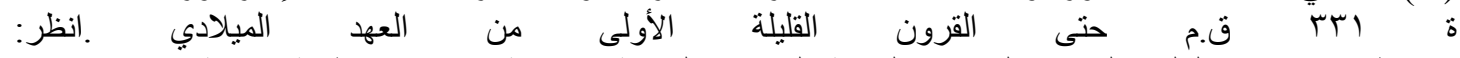

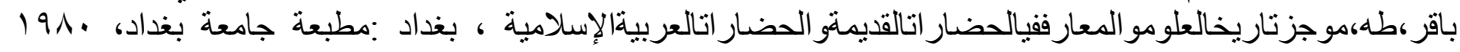

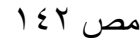

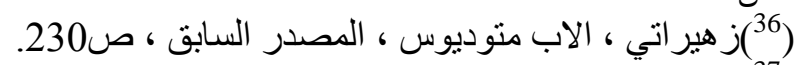

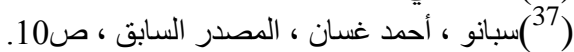
(35)

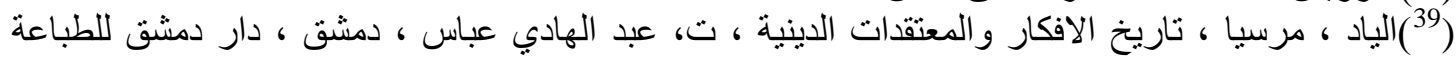

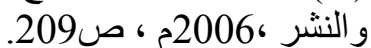

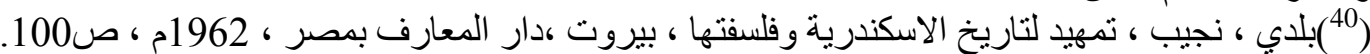

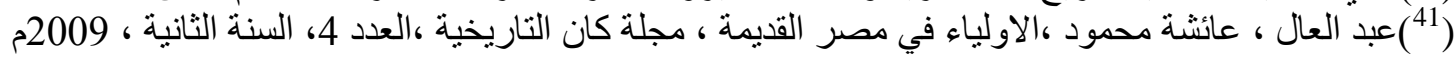

$$
\text { (42) }
$$

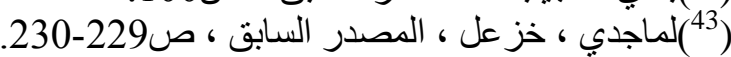

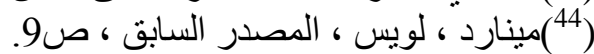

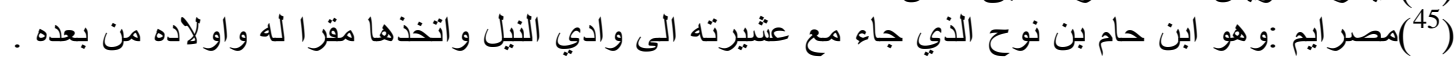

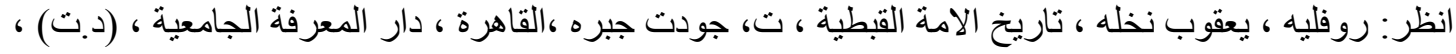

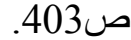
(464)الثناوي ، محمود أيوب ، الدين في الحضار ات القديمة ، مصر ، دار الكتب المصرية ، 2002م ، ص63-

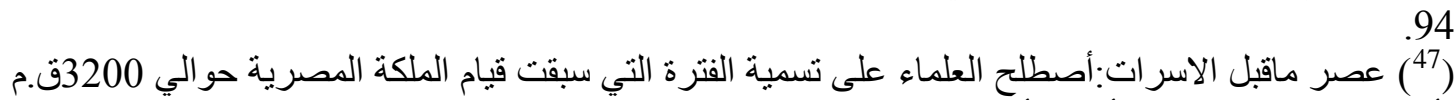

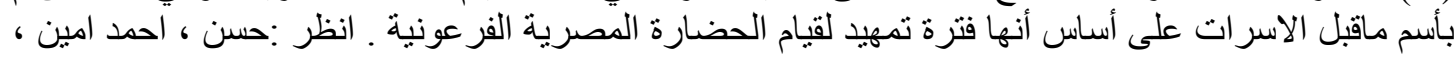

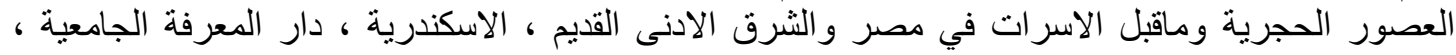

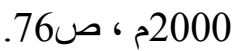
(48) (صالح، عبد العزبز ، التربية و التعليم في مصر القديمة ، القاهر ، الدار القومية للطباعة ، 1978م ، ص41 ص4.

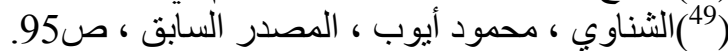

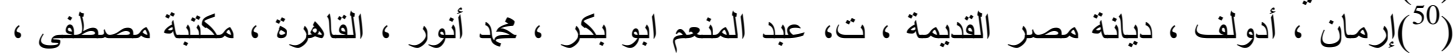

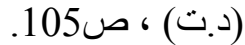

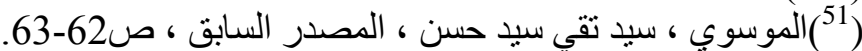
(52) مر اد ، سعيد ، المدخل في تاريخ الاديان ، القاهرة ، عين للار اسات و البحوث الانسانية و الاجتماعية ، (د.ت) ، (211) ص 210

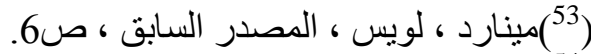

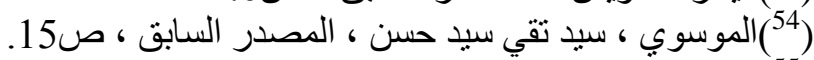
(56)

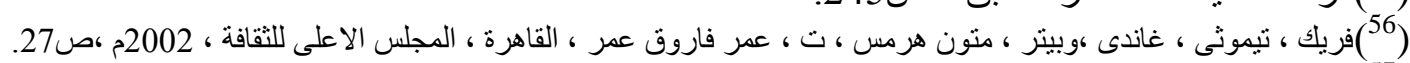

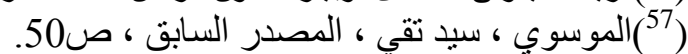

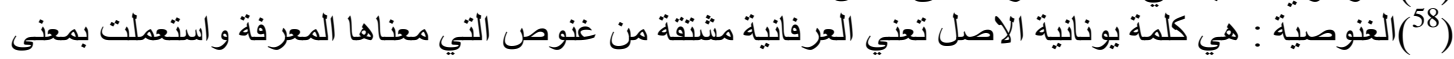

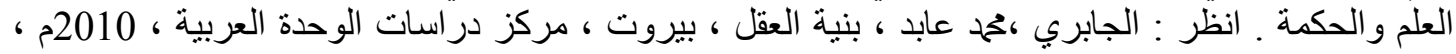
صن.354. (27) 


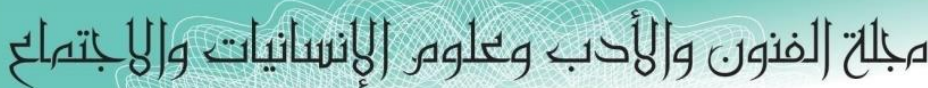

Journal of Arts, Literature, Humanities and Social Sciences

ISSN online: 2414 - 3383

ISSN print: 2616 - 3810

\section{العدد (42) أيلول - لسبتمبر 2019}

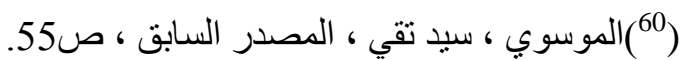

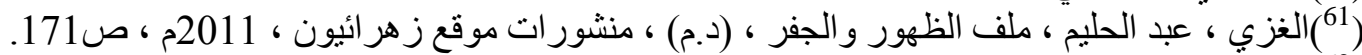
(62) البلخي ، أبي زيد أحمد بن سهل ، البدء والتاريخ ،لبنان ، بيروت ، دار الكتب العلمية ، 1997م ، ج1،

ص155. (155) - n

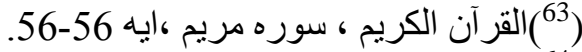

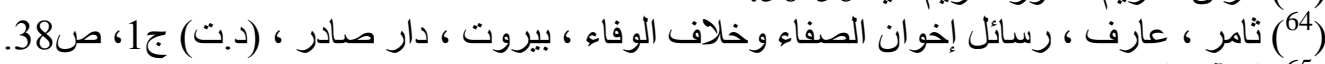

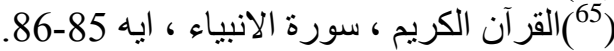

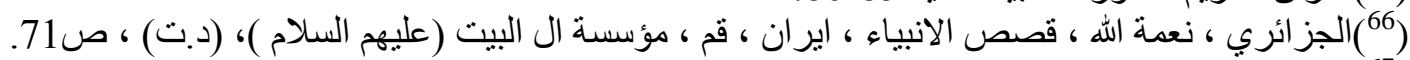

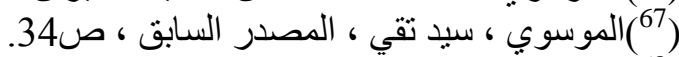

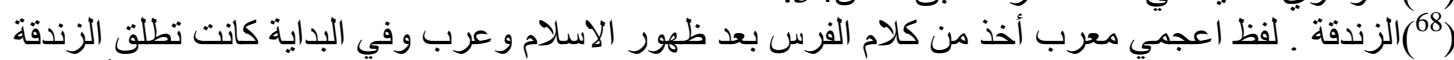

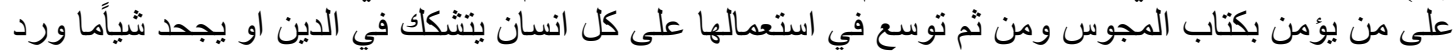

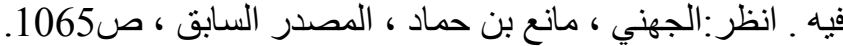

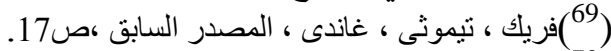

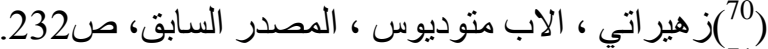

(11) ابن ابي اصيبعة ، موفق الدين ابي العيو العباس احمد بن القاسم ،عيون الاخبار ، بيروت ، دار الحياة ، 1965م ،

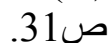

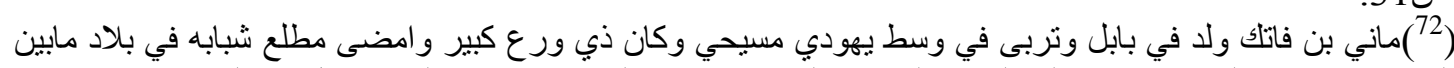

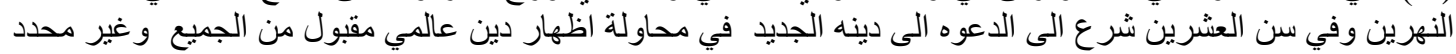

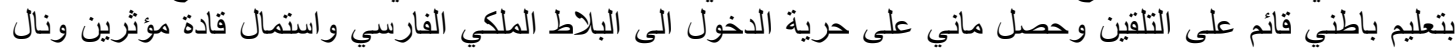

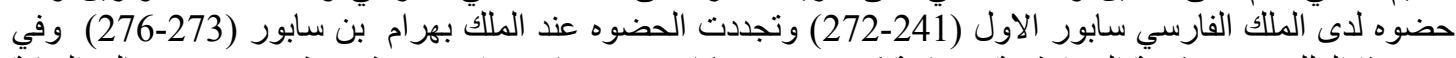

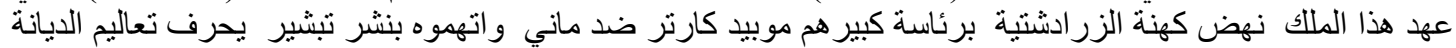

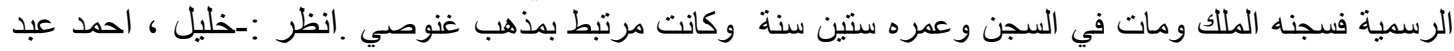

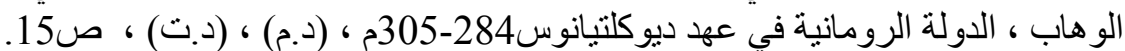

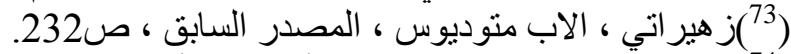

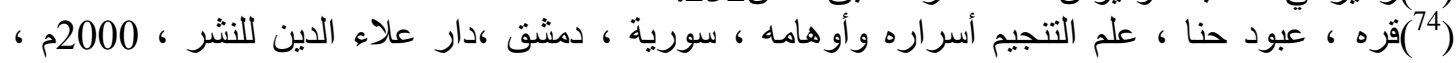

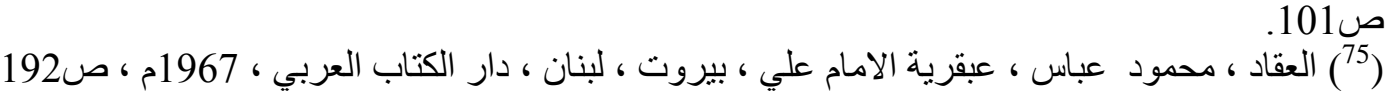

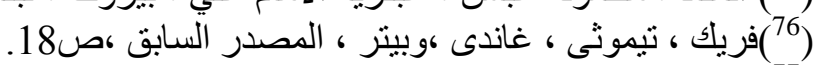

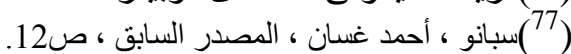

(78)

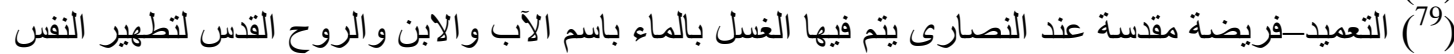

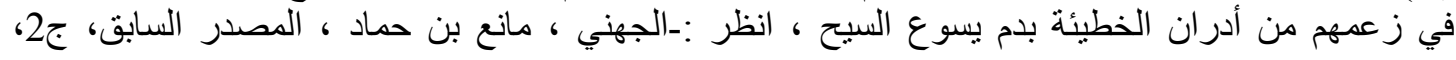

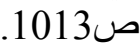

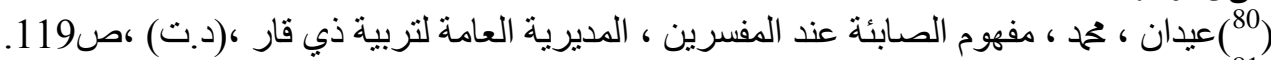

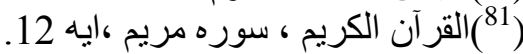

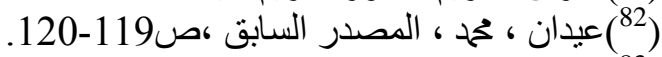

(83)

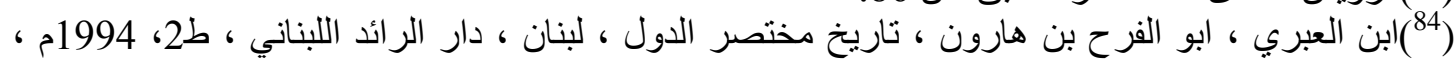

(85) (85) الموسوي ، سيد تقي ، المصدر السابق ، ص55.

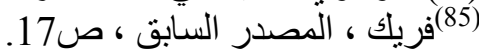

(86) الموسوي ، سيد تقي ، المصدر السابق ، ص55. 


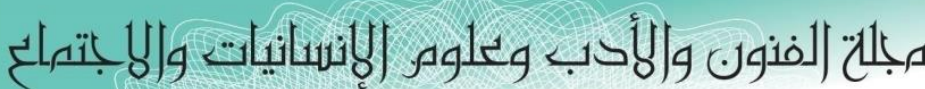

Journal of Arts, Literature, Humanities and Social Sciences

ISSN online: 2414 - 3383

ISSN print: 2616 - 3810

\section{العدد (42) أيلول - السبتهبر 2019}

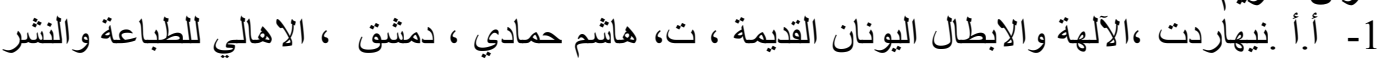

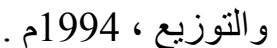

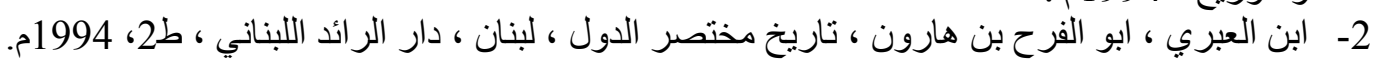

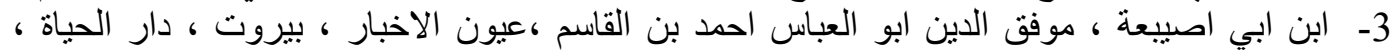

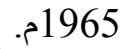

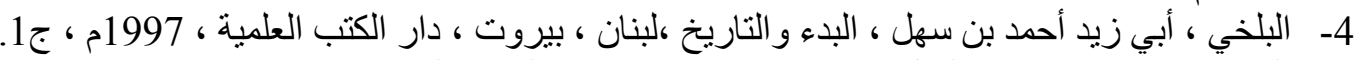

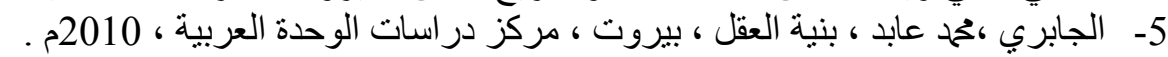

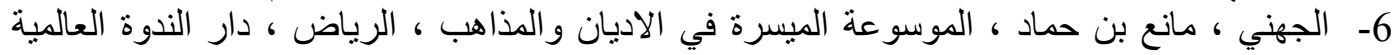

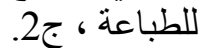

7- الجز ائري ، نعمة الله ، قصص الانبياء ، اير ان ، قم ، مؤسسة ال البيت (عليهم السلام )، (د.ت).

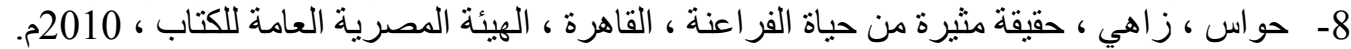

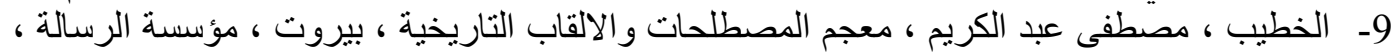
1996.

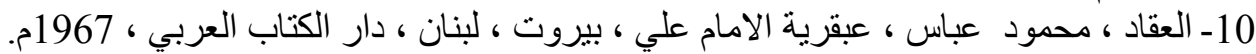

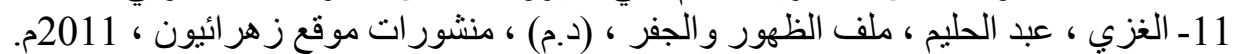

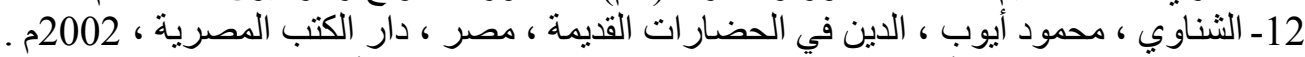

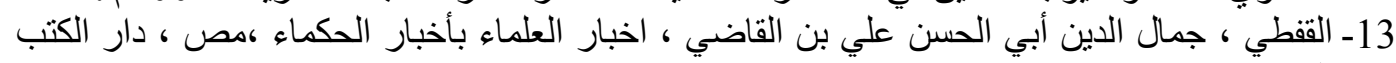

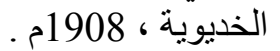

14ـ الماجدي ، خز عل ، كثف الحلقة المفقودة بين الاديان التعدد و التوحبد ، المغرب ، المركز الثقافي العربي . 2013،

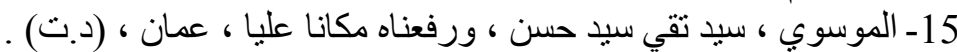

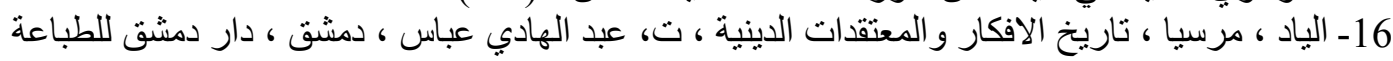

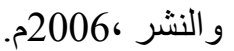

17- إرمان ، أدولف ، ديانة مصر القديمة ، ت، عبد المنعم ابو بكر ، محح أنور ، القاهرة ، مكتبة مصطفى ،

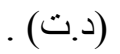

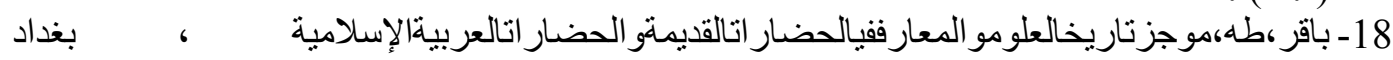

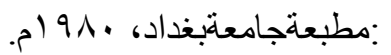

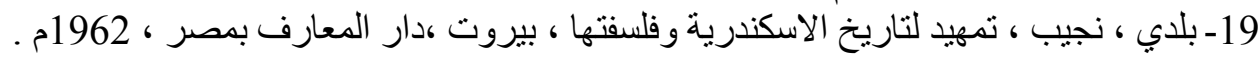
20- حسن ، احمد امين ، العصور الحجرية و ماقبل الاسر ات في مصر و الثربة الثرق الادنى القديم ، الاسكندرية ،

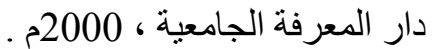

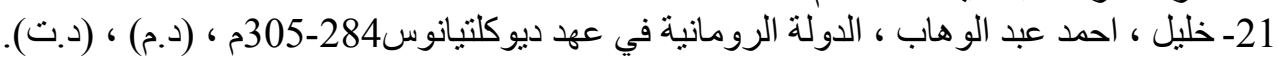

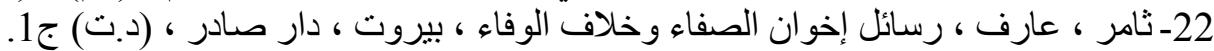

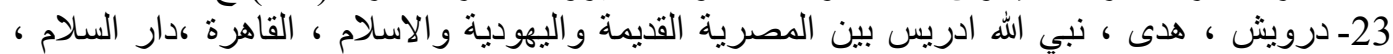
2008م.

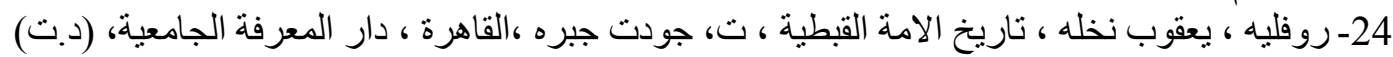

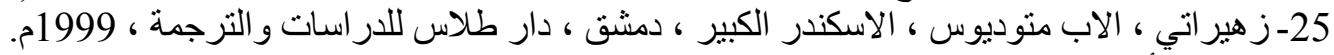

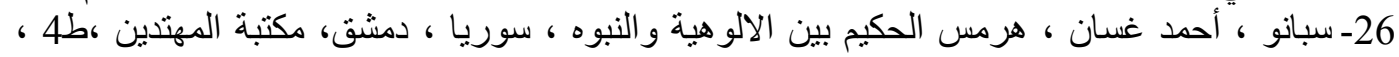
2010 
مبلحة لفنون والأدب وعلوه الإنسانيات و|لابتهماع

Journal of Arts, Literature, Humanities and Social Sciences

ISSN online: 2414 - 3383

ISSN print: 2616 - 3810

العدد (42) أيلول - سبتمبر 2019

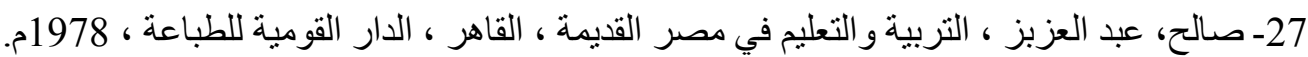

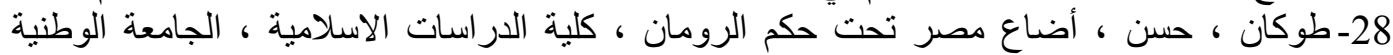

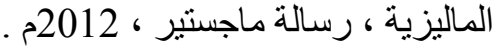

29- طوكان ، حسن ، عليعل ، باسم ، موقف الدولة اليونانية من اليهود ، مجلة ابحاث البصرة ، مج43،

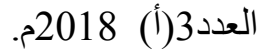

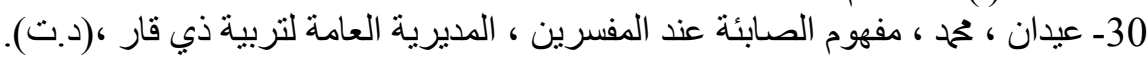

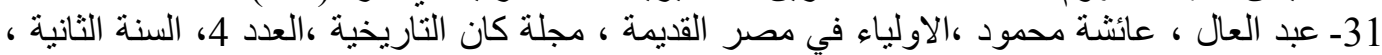
2009م.

32- فريك ، تيموثى ، غاندى ،وبيتر ، منون هرمس ، ت ، عمر فاروق عمر ، القاهرة ، المجلس الاعلى

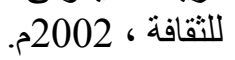

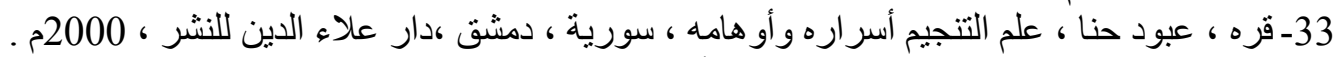

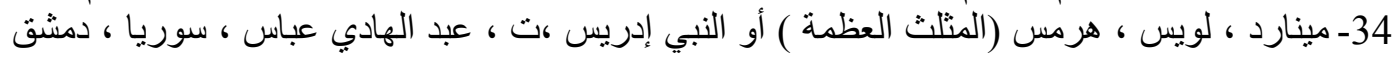

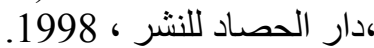

35- مير علم ، يحيى ، ابن وحشية النبطي وريادته في كثف رموز هيرو غليفية ،مجلة ديوان العرب ، (د.

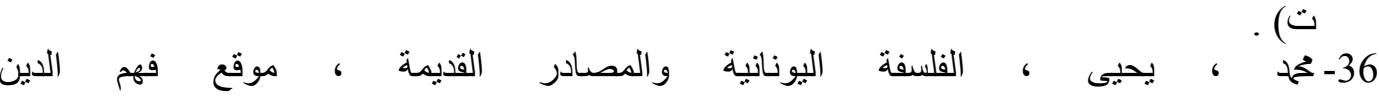
http://fahmaldin.net/index.php?id=2144

37- مر اد ، سعيد ، المدخل في تاريخ الاديان ، القاهرة ، عين للار اسات و البحوث الانسانية والاجتماعية ،

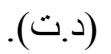

38- مرعي ،عيد ، معجم الالهة والكائنات الاسطورية في الثرق الادنى القديم ، دمثق ، الهيئة العامة

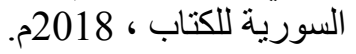

39- مالمات ، ابر اهام ، حييم تدمور ، العبر انبون وبنو اسر ائيل في العصور القديمة ، ت ، رشاد الثامي ،

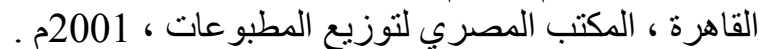

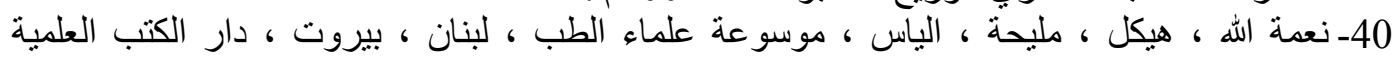
1991، 